\title{
Tick Size Reduction and the Components of the Bid-Ask Spread on the Taiwan Stock Exchange
}

\author{
$\mathrm{Su}-\mathrm{Wen} \mathrm{Kuo}^{1}$ \\ ${ }^{1}$ Department of Finance, Ling Tung University of Science and Technology, Taiwan \\ Correspondence: Su-Wen Kuo, Department of Finance, Ling Tung University of Science and Technology, 1, Lingtung \\ Road, Nantun District, 40852 Taichung City, Taiwan. Tel: +886-4-23892088\#1771. \\ Received: December 3, 2016 \\ Accepted: December 23, 2016 \\ Online Published: December 30, 2016 \\ doi:10.5430/ijfr.v8n1p79 \\ URL: http://dx.doi.org/10.5430/ijfr.v8n1p79
}

\begin{abstract}
We examined the effect of reduced tick size on spread and its various components on Taiwan Stock Exchange (TWSE). The TWSE stands for a representative order-driving call mechanism in the emerging market. The noticeable market features of the TWSE render our findings on the effect of tick-size changes useful in combination with those reported in studies on developed markets. Our evidence strongly indicated that the traded spread and the order-processing component declined after tick size was reduced, whereas the asymmetric information component exhibited less significant changes. We documented a relatively high proportion of the order-processing component of the TWSE compared with that observed in developed markets after tick size was reduced. The cross-sectional regression analysis results indicated that stocks with high binding constraints, a high price, and high trading activity generated substantial savings on the order-processing component after tick-size conversion. Our empirical results highlight the important contributions of reduced tick size on market efficiency specifically in an emerging call market setting.
\end{abstract}

Keywords: tick size, traded spread, order-processing costs, asymmetric information costs

\section{Introduction}

The asset exchange process inevitably entails spreads consisting of transaction costs paid by market participants and economic rents charged by liquidity providers. Market microstructure research has focused on the content and estimation of spreads and their various components: order-processing, asymmetric information, and inventory holding costs. Stoll (1978) defined order-processing costs as the charge that dealers must implement to compensate for the fixed costs of liquidity provision. Gibson, Singh, and Yerramilli (2003) considered order-processing costs as the sum of fixed costs combined with residual variable costs, such as economic rent earned by market makers using market power. The asymmetric information component of bid-ask spreads is the compensation for dealers who typically generate trading losses when confronting informed traders. Kyle (1985) and Glosten and Milgrom (1985) have demonstrated that information asymmetry can be measured according to the relative ratio of informed traders to noise traders, and that wide spreads accurately reflect the transaction risk of market makers in a relatively disadvantaged position when facing informed traders. Gibson et al. (2003) similarly postulated that adverse-selection costs generate a positive association with the degree of information asymmetry. Huang and Stoll (1997) reported that competition among multiple dealers can mitigate market asymmetry and reduce the adverse-selection component. Van Ness, Van Ness, and Warr (2001) demonstrated that volatility generates a significant positive relationship with asymmetric information and appropriately proxies adverse-selection risk. Finally, the inventory-holding component measures dealer compensation when a dealer possesses an insufficiently diversified portfolio. O'Hara and Oldfield (1986) presumed that dealers adjust the spread size to accommodate their net positions and accounted for relevant inventory risks. Inventory holding costs generally have a positive association with volatility and trade size, but a negative relationship with trading frequency and traded options. Madhavan and Smidt (1991) and George, Kaul, and Nimalendran (1991) have suggested that inventory holding costs are relatively negligible compared with those of their empirical samples.

Numerous methods for estimating the spread components have been successfully developed and implemented in various applications. For example, George et al. (1991) extended the Glosten and Harris (1988) study and reported that $87 \%$ to $92 \%$ of the total spread on the AMEX and NYSE can be ascribed to order-processing costs and the remaining $8 \%$ to $13 \%$ can be attributed to asymmetric information costs, combined with the negligible inventory-holding component. George et al. (1991) concluded that order-processing costs were the primary component of the quoted spread. However, Lin, Sanger, and Booth (1995) employed a set of the largest 150 NYSE 
firms and reported the sizes of the asymmetric information component and order-processing component to be approximately 35\% and 33\%, respectively. Huang and Stoll (1997) used a ready-made sample of 20 of the largest and most actively traded stocks in the NYSE, and determined the three-way decomposition estimates to be $61.8 \%$, $28.7 \%$, and $9.6 \%$ for the order-processing, inventory-holding, and adverse-selection components, respectively. Madhavan, Richardson, and Roomans (1997) extended the indicator model of Glosten and Milgrom (1985) to correlate the order flow in their model. They employed a sample of 274 firms in the NYSE and estimated the size of the adverse-selection component to be approximately $43 \%$, whereas the average transaction cost comprised the remaining $57 \%$.

These documents were obtained from markets under a tick size of one-eighth or one-sixteenth of a dollar. Stock exchanges worldwide have recently adopted a smaller minimal price variation to reduce transaction costs and promote trading activity. A wide array of financial studies has been devoted to the effects of reduced tick size on traded spreads and their various components. Gibson et al. (2003) suggested that reduced spreads caused by converting decimal pricing on NYSE-listed S\&P 500 stocks have resulted in a significant decline in the residual order-processing component and less substantial changes in the inventory combined with asymmetric-information component. Jiang, Kim, and Wood (2009) compared changes in the adverse-selection component between NASDAQ and NYSE after decimalization, and observed a significant reduction in the adverse-selection component compared with that of the NYSE because the arrival of order flows significantly differed. Ahn, Cai, Chan, and Hamao (2007) observed that the order-driven Tokyo Stock Exchange (TSE) experienced quoted spread and effective spread reductions of $20 \%$ to $50 \%$, and $24 \%$ to $60 \%$, respectively, after the tick-size change. Although the order-processing component and the asymmetric information component declined simultaneously, the reduced spread was largely attributed to the diminished order-processing component. The resultant proportional per share asymmetric information component of TSE spreads has consequently increased from $31.54 \%$ to $43.83 \%$. By further investigating the influence of endogenous tick-size change in TSE, Cai, Hamao, and Ho (2008) obtained a similar result and concluded that much of the dramatic changes in the spread, for stocks with approximate ¥1000, can largely be attributed to substantial changes in the order-processing components. Because most previous research has disproportionally targeted quote-driven markets among developed markets, empirical studies in the context of pure limit-order emerging markets are extremely limited. The present study anatomically examined tick-size changes in the TWSE to provide positive evidence and insights into this topic.

The TWSE has officially promulgated new minimal price variations since March 1, 2005. Prior to the changes, the minimal relative tick size among the nine price categories varied from $0.1 \%$, the smallest, to $0.5 \%$, the largest.

Table 1. Absolute and relative tick size on the TWSE following the tick size reduction *

\begin{tabular}{|c|c|c|c|c|c|c|}
\hline & \multirow{2}{*}{ Groups } & \multirow{2}{*}{$\begin{array}{c}\text { Price Range } \\
\text { (NT\$) }\end{array}$} & \multicolumn{2}{|c|}{ Absolute Tick Size } & \multicolumn{2}{|c|}{ Relative Tick Size } \\
\hline & & & $\operatorname{Pre}(\mathrm{NT} \$)$ & Post(NT\$) & $\operatorname{Pre}(\%)$ & $\operatorname{Post}(\%)$ \\
\hline 1 & (Control group) & $0-5$ & 0.01 & 0.01 & $0.2-100$ & $0.2-100$ \\
\hline 2 & & $5-10$ & 0.05 & 0.01 & $0.5-1$ & $0.1-0.2$ \\
\hline 3 & (Control group) & $10-15$ & 0.05 & 0.05 & $0.334-0.5$ & $0.334-0.5$ \\
\hline 4 & & $15-50$ & 0.1 & 0.05 & $0.2-0.667$ & $0.1-0.333$ \\
\hline 5 & & $50-100$ & 0.5 & 0.1 & $0.5-1$ & $0.1-0.2$ \\
\hline 6 & (Control group) & $100-150$ & 0.5 & 0.5 & $0.334-0.5$ & $0.334-0.5$ \\
\hline 7 & & $150-500$ & 1 & 0.5 & $0.2-0.667$ & $0.1-0.333$ \\
\hline 8 & (Control group) & $500-1,000$ & 1 & 1 & $0.1-0.2$ & $0.1-0.2$ \\
\hline 9 & (Control group) & Over 1,000 & 5 & 5 & $<0.5$ & $<0.5$ \\
\hline
\end{tabular}

Note: $*$ The table lists the tick sizes for the nine price categories before and after the TWSE reduced the minimal tick size on March 1, 2005, the effective date for implementing the new tick-size rule.

Among the new tick sizes, five of the nine price categories have reduced the tick sizes of Group 2 (NT\$5-10) by $80 \%$ (from NT\$0.05 to NT\$0.01); Group 4 (NT\$15-50) by 50\% (from NT\$0.1 to NT\$0.05); Group 5 (NT\$50-100) by $80 \%$ (from NT\$0.5 to NT\$0.1), and Group 7 (NT\$150-500) by 50\% (from NT\$1 to NT\$0.5). Because of the diminished tick size, the minimal relative tick size among the nine price categories on the TWSE has been smoothed out from the smallest, $0.1 \%$, to the largest, $0.334 \%$. 
We fully capitalized on the natural experimental opportunity offered by the TWSE to examine the effects of tick-size changes on the associated traded spread and their various components. Among the various spread decomposition models, we employed that developed by George, Kaul, and Nimalendran (GKN, 1991), which was derived from the serial covariance properties of observed transaction prices; and the models presented by Huang and Stoll (HS, 1997) and Madhavan, Richardson, and Roomans (MRR, 1997), both of which were based on trade initiation indicator variables and their related proxies. They decomposed total spreads into permanent components, including information asymmetry costs and transitory components, in addition to order-processing costs and inventory-holding costs. Hasbrouck (1988), Madhavan and Smidt (1991), and George et al. (1991), estimated that inventory holding costs were relatively negligible, and we believed the estimation was particularly applicable to the TWSE where most transactions are executed using limit order books without the assistance of dealers and market makers. We focused on the components of order-processing costs and asymmetric information costs in our analysis.

We examined the effects of tick-size changes on the various components of traded spread in the TWSE for clarifying whether tick-size systems affect market competition on the limit order book and how liquidity providers can earn economic rents from liquidity provision when an order-driven mechanism is in effect. Anshuman and Kalay (1998) observed that liquidity providers can obtain abnormal profits from order-handling processes and that cost saving achieved because of the reduced tick size was largely attributable to reduced economic rents previously captured by liquidity provision before decimal pricing. Gibson et al. (2003) discovered that in fractional pricing regime, market makers maintained spreads that were artificially too high and earned the extra rent component. The substantial decrease in order-processing costs observed after the decimal tick-size regime was implemented caused market competition to intensify among dealers and limit order book traders and weakened the ability of market makers to obtain additional profits. We investigated whether reduced tick size encouraged or discouraged trader incentives of information acquisition. A smaller tick size in the TWSE might cause informed traders to pay less in spread and to encounter a low probability of the spread straddling the efficiency price; both can encourage information gathering. Heflin and Shaw (2001) asserted a similar argument, suggesting that a thin limit order book might cause market volatility and stimulate more information acquisition. By contrast, a smaller price variation can also reduce the costs of front running and quote matching in the limit order book and therefore reduce the motivation for collecting information. Whether reduced tick size encourages or discourages information collecting can be resolved by using empirical examination only. Therefore, we empirically investigated the effect of TWSE tick-size conversion on the incentives of acquiring information.

The results indicated that the traded spread significantly narrowed after the tick size was reduced and market traders largely improved by smaller transaction costs. We also determined that the reduced traded spread was largely attributed to the diminished order-processing component because the asymmetric information components remained relatively scant before and after tick-size conversion. In addition, we discovered that the high-priced Group 5 obtained the highest proportional reduction of the order-processing and asymmetric-information component, whereas it retained the highest proportional order-processing component for liquidity provision. We argued that high-priced stocks attract greater market liquidity and can be traded at low costs without exposing excessive adverse selection. Under smaller minimum price variation, the liquidity provision in the high-priced group might compensate $r$ the loss of economic rent and regain Pareto improvement as demonstrated in Bacidore (1997).

TWSE represents a primary trading protocol among emerging markets. After reducing tick size, the average per share proportion of the asymmetric information component to the traded spread significantly increased from $17.856 \%$ to $21.453 \%, 9.505 \%$ to $11.578 \%$, and $12.348 \%$ to $14.643 \%$ for GKN, HS, and MRR, respectively. As typical examples of developed markets, Gibson et al. (2003) reported 59.04\% asymmetric information in the NYSE and Ahn et al. (2007) documented $43.21 \%$ in the TSE after tick size was reduced. The present empirical evidence indicated that a relatively large order-processing component remained for liquidity provision in the TWSE limit order book. We consequently conjectured that the minimal price variation can still be further reduced, and that the optimal tick size of the TWSE is worthy of more deliberate consideration among market traders, regulators, and researchers.

We focused on the effect of tick-size changes on institutional traders, which previous studies have not completely resolved. Goldstein and Kavajecz (2000), Jones and Lipson (2001), and Bollen and Busse (2006) have documented that trading costs for actively managed mutual funds and large order trading in the NYSE have become more expensive after decimalization. Kadan (2006) presented a deal-market model to investigate who profits from a smaller tick size and determined that decreased tick size benefited dealers, whereas it typically hurt public investors when the number of dealers for a stock was small. The present results demonstrated that the traded spread and the order-processing component monotonically increased with the trade size during previous and post tick-size regimes. This evidence further implied that reduced tick size generated greater cost-savings for retail traders than for institutional traders because the magnitudes of the reduced traded spread and order-processing component were inversed to trade size.

The present study focused on a representative order-driving call mechanism in the emerging market. The TWSE 
possesses noticeable market features that render our findings on the effect of tick-size changes useful in combination with those reported in studies on developed markets, including the NYSE, NASDAQ, and TSE. First, the TWSE implemented a pure, order-driven call market without designated market makers, and all limit orders are submitted by public traders, whereas market orders are suspended from price determination. Comerton-Forde and Rydge (2006) have indicated that the TWSE trading mechanism solely uses the call auction for intraday trading and for market openings and closings, which is unique among Asia-Pacific stock markets. Second, the TWSE adopted strict measures for ensuring market stability; the most notable are daily $7 \%$ price limits, short-selling restrictions, and margining systems for stock transactions. Third, Rhee and Chang (1992) reported that the TWSE maintains the lowest security transaction cost in the Asia-Pacific region, which might explain the persistently high turnover rates observed in the TWSE. Finally, the TWSE has persistently experienced an unusually high proportion of retail transactions. Prior to 1998, the proportion exceeded $90 \%$ and remained at $70 \%$ in 2009 after great efforts to promote institutional participation, particularly by foreign institutions. Crouhy and Galai (1992) suggested that the market microstructure could crucially affect the short-term behavior of stock returns, and we believe that these TWSE features provide a valuable opportunity for examining the relationship between tick size and spread components.

We analyzed the cross-sectional idiosyncratic attributes of trading activity, competition, and information structure related to the effect of reduced tick size. The results indicated that a high probability of binding constraint, price level, number of trades, and trade size further reduces the order-processing component after tick-size conversion. By contrast, the individual idiosyncratic attributes exerted less significant influences on the asymmetric information costs incurred because of the reduced tick size.

The remainder of this paper is organized as follows. Section 2 presents a description of the empirical data and models; Section 3 presents a report and analysis of the empirical results; and Section 4 offers a conclusion and remarks.

\section{Data and Methodology}

\subsection{Data and Sample Selection}

We used a set of intraday tick-by-tick transaction and quote data obtained from the Taiwan Economic Journal (TEJ) for analyzing the effects of tick-size changes. The TWSE launched the new system of minimal price variation on March 1, 2005. This study covered the 3-month periods before and after the effective date. Moreover, the data excluded information on the 5 trading days immediately before and after the event date to avoid any temporary behavioral bias caused by the effect of tick-size changes. The sample comprised 52 trading days in the preevent period (December 1, 2004 to February 18, 2005) and 59 trading days in the postevent period (March 8 to May 31, 2005). To check for robustness, we empirically examined a sample comprising data on the entire year, 6 months prior to and after the date of tick-size conversion. This sample was composed of 697 TWSE listed companies. To prevent data contamination, we used a set of specific sample selection criteria for excluding sample firms: (a) the new IPOs were less than 3 months prior to the sample period; (b) the average daily trading volume was less than $5 \%$ of the average for the total sample; and (c) the highest or lowest prices were located in two or more price notches during the sample period. Furthermore, to filter out noises of errant trading during the open and closed market, we excluded the 5-min periods after the market opened and prior to the market closing. Based on these criteria, relatively few companies in the price categories realized a price above NT $\$ 100$. We therefore focused on comparing the test groups (Groups 2, 4, and 5) with the control groups (Groups 1 and 3).

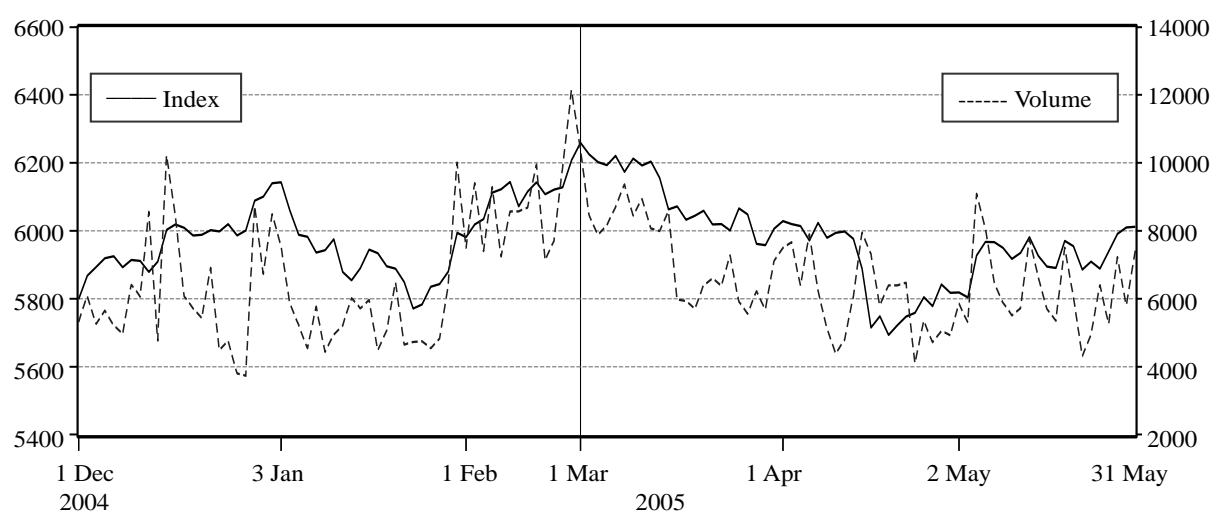

Figure 1. Daily TAIEX index and total trading volume on the TWSE

Note: The figure plots the daily TAIEX index and total volume on the TWSE (in NT\$10 million) over the 6-month period from December 1, 2004 to May 31, 2005. The vertical line, centered on March 1, 2005, indicates the date on which the TWSE implemented the new tick-size rule. 
Figure 1 indicates that the TAIEX index and its daily trading volume were relatively stable during the period and no material changes are observable during the tick-size change. This evidence ensures that the minimal price variation conversion was the major market microstructure innovation affecting the TWSE during the period under examination.

Table 2. Spreads, depth and trading activity in the pre- and post- tick size reduction periods ${ }^{\mathrm{a}}$

\begin{tabular}{|c|c|c|c|c|}
\hline Variables & Pre & Post & $\%$ Change $^{\mathrm{c}}$ & p-value \\
\hline \multicolumn{5}{|l|}{ Group $1(\mathrm{n}=15)($ Control group) } \\
\hline Effective spread(dollar) & 0.035 & 0.037 & 6.04 & - \\
\hline Quoted depth(1000 shares) & 7,553 & 6,252 & -17.211 & - \\
\hline No. of Trades & 132.1 & 102.8 & -22.13 & - \\
\hline Share Volume(1000 shares) & 910 & 770 & -15.35 & - \\
\hline NT\$ Volume(million NT) & 2,896 & 2,257 & -22.05 & - \\
\hline Trade Size(1000 shares) & 7.11 & 6.31 & -11.19 & - \\
\hline \multicolumn{5}{|l|}{ Group $2(\mathrm{n}=39)$} \\
\hline Effective spread(dollar) & 0.056 & 0.039 & $-30.48 * *$ & 0.000 \\
\hline Quoted depth(1000 shares) & 79,841 & 10,317 & $-87.08 * *$ & 0.000 \\
\hline No. of Trades & 344.5 & 297.2 & -13.73 & 0.699 \\
\hline Share Volume(1000 shares) & 2551 & 1950 & -23.56 & 0.575 \\
\hline NT\$ Volume(million NT) & 20,036 & 15,544 & -22.42 & 0.334 \\
\hline Trade Size(1000 shares) & 6.14 & 5.63 & $-8.32 *$ & 0.549 \\
\hline \multicolumn{5}{|l|}{ Group $3(n=28)$ (Control group) } \\
\hline Effective spread(dollar) & 0.060 & 0.065 & $8.39 *$ & - \\
\hline Quoted depth(1000 shares) & 102,864 & 76,758 & $-25.38: *$ & - \\
\hline No. of Trades & 572.2 & 511.0 & -10.70 & - \\
\hline Share Volume(1000 shares) & 3947 & 3508 & -11.11 & - \\
\hline NT\$ Volume(million NT) & 52,398 & 45,896 & -12.41 & - \\
\hline Trade Size(1000 shares) & 5.35 & 5.43 & 1.51 & - \\
\hline \multicolumn{5}{|l|}{ Group $4(n=184)$} \\
\hline Effective spread(dollar) & 0.109 & 0.079 & $-27.39 * *$ & 0.000 \\
\hline Quoted depth(1000 shares) & 154,304 & 52,899 & $-65.72^{* * *}$ & 0.010 \\
\hline No. of Trades & 934.0 & 919.4 & -1.56 & 0.096 \\
\hline Share Volume(1000 shares) & 4812 & 4291 & $-10.82 *$ & 0.328 \\
\hline NT\$ Volume(million NT) & 129,318 & 118,781 & -8.15 & 0.336 \\
\hline Trade Size(1000 shares) & 4.08 & 3.88 & $-5.01 *$ & 0.042 \\
\hline \multicolumn{5}{|l|}{ Group $5(\mathrm{n}=24)$} \\
\hline Effective spread(dollar) & 0.495 & 0.144 & $-70.85 * *$ & 0.000 \\
\hline Quoted depth(1000 shares) & 593,070 & 50,465 & $-91.49 * *$ & 0.000 \\
\hline No. of Trades & 770.7 & 1129.9 & $46.61 * *$ & 0.001 \\
\hline Share Volume(1000 shares) & 3515 & 3985 & 13.35 & 0.018 \\
\hline NT\$ Volume(million NT) & 230,942 & 278,795 & $20.72 *$ & 0.012 \\
\hline Trade Size(1000 shares) & 3.74 & 3.05 & $-18.54 * *$ & 0.000 \\
\hline
\end{tabular}

Notes:

a Each of the variables were calculated for the 3-month periods prior to and after March 1, 2005, the date on which the new tick-size rule became effective in the TWSE, along with the \% change between the pre- and post- periods.

b The $P$ values of the Wilcoxon rank-sum test under the null hypothesis: the designated variables of the control groups and test groups are equal (i.e., Group 1 vs. Group 2, Group 3 vs. Group 4, and Group 3 vs. Group 5).

c ${ }^{*}$ and ${ }^{* *}$ indicate a $5 \%$ and $1 \%$ significance level, respectively. 
Table 2 lists the basic statistics of effective spread, quoted depth, and trading activity before and after the TWSE reduced the minimal price variation. The effective spreads of Groups 2, 4, and 5 significantly reduced by $30.48 \%$, $27.39 \%$, and $70.85 \%$, respectively. The quoted depths exhibited a greater decline of $87.08 \%, 65.72 \%$, and $91.49 \%$. The last column of Table 2 documents the Wilcoxon rank-sum test results and displays the significant differences between the test groups and control groups (Group 1 versus Group 2, Group 3 versus Group 4, and Group 3 versus Group 5) in the proportion changes of effective spread and quoted depth. The smaller tick size reduced the probability of binding constraints and intensified market competition, resulting in a smaller effective spread. The reduced tick size drained the revenue of per share liquidity provision and increased the risk of order exposure, thereby decreasing the depth of the limit order book, as predicted by Harris (1994). Regarding trading activity, trade size uniformly displayed significant decreases in the test groups, and diminished to the greatest by $18.54 \%$ in the high-priced Group 5. The Wilcoxon rank-sum tests also indicated significant differences among the test groups and control groups (Group 3 versus Group 4, and Group 3 versus Group 5). The trade-size results demonstrated that informed traders employed a smaller trade size to hide private information, or that front-runners placed a smaller trade size to avoid market turbulence when facing tighter spreads and a thinner limit order book in the narrowing tick-size regime, as indicated by Kuo, Huang, and Chen (2010). However, the number of trades and the amount of trading volume exhibited mixed results among the three test groups and resulted in significance for the high-priced Group 5 only. The evidence of trading activity conducted by Group 5 indicated that reduced tick size might cause liquidity suppliers to split orders into smaller sizes to avoid front running. Under a reduced quoted spread and a thinner limit order book, the increased number of trades and amount of dollar trade volume might indicate Pareto improvement because of the aggressive involvement of buy-side traders and liquidity providers in the market, and because the benefits from lower transaction costs and higher trading volume compensate for the loss of economic rent.

\subsection{Decomposition of the Bid-Ask Spreads}

We comparatively applied the models proposed by George, Kaul, and Nimalendran (1991; hereafter, GKN); Huang and Stoll (1997; hereafter, HS), and Madhavan, Richardson, and Roomans (1997; hereafter, MRR) as the decomposition models of the bid-ask spreads. The following provides a brief description of the models, and the details are described in McInish and Van Ness (2002) and Gibson et al. (2003). (Note 1)

\section{i. GKN model-------- George, Kaul, and Nimalendran (1991)}

GKN demonstrated that the difference between transaction returns and quote midpoint returns can be used to filter out the serial dependence in returns. The resulting estimate of the components of the bid-ask spread is expressed as

$$
2 \mathrm{RD}_{\mathrm{t}}=\pi \mathrm{S}_{\mathrm{q}, \mathrm{t}}\left(\mathrm{D}_{\mathrm{t}}-\mathrm{D}_{\mathrm{t}-1}\right)+\mathrm{e}_{\mathrm{t}}
$$

where $R D_{t}$ is the difference between transaction returns and quote midpoint returns immediately following the transaction return at time $t, \pi$ is the order-processing component, $1-\pi$ is the asymmetric information component, $\mathrm{S}_{\mathrm{q}, \mathrm{t}}$ is the percentage quoted bid-ask spread, and $e_{t}$ is the disturbance term. $D_{t}$ is the trade indicator at time $t$, which is equal to 1 if the trade is buyer initiated and -1 if the trade is seller initiated. The initiation of trading was estimated using the algorithm presented by Lee and Ready (1991).

Adding an intercept to the aforementioned equation and relaxing the assumption that $S_{q}$ is constant gives

$$
2 \mathrm{RD}_{\mathrm{t}}=\pi_{0}+\pi_{1} \mathrm{~S}_{\mathrm{q}, \mathrm{t}}\left(\mathrm{D}_{\mathrm{t}}-\mathrm{D}_{\mathrm{t}-1}\right)+e_{t}
$$

The traded spread, AI, and OP components of the spread are calculated for each stock i using the GKN model:

$$
\begin{array}{ll}
\text { GKNS }=\text { Quoted spread } & (\text { dollar }) \\
\text { GKNAI }=\left(1-\pi_{l}\right) \cdot \text { Quoted spread } & (\text { dollar }) \\
\text { GKNOP }=\pi_{l} \text { Q Quoted spread } & (\text { dollar })
\end{array}
$$

\section{ii. HS model---------- Huang and Stoll (1997)}

Huang and Stoll (1997) categorized traded spreads and decomposed traded spreads into an order-processing component and an inventory combined with adverse-selection component as follows. The lists of related notations are listed as follows:

- $\mathrm{V}_{\mathrm{t}}$ : the unobservable fundamental value of the stock at time $\mathrm{t}$ in the absence of transaction costs;

- $\mathrm{M}_{\mathrm{t}}$ : quote midpoint at time $\mathrm{t}$, computed as the average of the bid and ask;

- $\mathrm{P}_{\mathrm{t}}$ : actual observed transaction price at time $\mathrm{t}$; 
- S: the traded spread for the stock;

- $\alpha$ : the percentage of $S / 2$ attributable to adverse-selection costs;

- $\beta$ : the percentage of $\mathrm{S} / 2$ attributable to inventory costs;

- $\lambda$ : the percentage of $S / 2$ attributable to adverse-selection and inventory costs. $(\alpha+\beta)$;

- 1- $\lambda$ : the percentage of $\mathrm{S} / 2$ attributable to order-processing costs.

The market maker must bear the adverse-selection costs and the inventory costs, which depend on the direction of the trade. Thus, for a unit positive buyer-initiated trade, the market maker revises the estimate of $V_{t}$ upwards by an amount of $\alpha \cdot S / 2$. The buyer-initiated trade on average reduces the inventory of the market maker, thus rendering the market maker less anxious to trade in that direction. This effect is evidenced by the market maker adjusting the midpoint of the spread upwards by an amount of $\beta \cdot S / 2$. By combining the two amounts, the following is derived:

$$
\mathrm{M}_{\mathrm{t}}=\mathrm{M}_{\mathrm{t}-1}+(\alpha+\beta)(\mathrm{S} / 2) \mathrm{D}_{\mathrm{t}-1}+\varepsilon_{t}
$$

The observed transaction price depends on the direction of the trade. A buyer-motivated trade occurs at the tradable ask $\left(M_{t}+S / 2\right)$, whereas the seller-motivated trade occurs at the tradable bid $\left(M_{t}-S / 2\right)$. Thus,

$$
\mathrm{P}_{\mathrm{t}}=\mathrm{M}_{\mathrm{t}}+\mathrm{S} / 2 \mathrm{D}_{\mathrm{t}}+\eta_{t}
$$

where $\eta_{t}$ represents the deviation of the observed half-spread, $P_{t}-M_{t}$, derived from the constant half-spread, $S / 2$, and includes rounding errors associated with the minimal tick size. The first difference of this equation yields

$$
\Delta P_{t}=\Delta M_{t}+S / 2\left(D_{t}-D_{t-1}\right)+\Delta \eta_{t}
$$

By substituting this into (2), we obtain the model estimation:

$$
\begin{aligned}
\mathrm{P}_{\mathrm{t}}-\mathrm{P}_{\mathrm{t}-1} & =(\alpha+\beta)(\mathrm{S} / 2) \mathrm{D}_{\mathrm{t}-1}+(\mathrm{S} / 2)\left(\mathrm{D}_{\mathrm{t}}-\mathrm{D}_{\mathrm{t}-1}\right)+e_{t} \\
& =\lambda(\mathrm{S} / 2) \mathrm{D}_{\mathrm{t}-1}+(\mathrm{S} / 2)\left(\mathrm{D}_{\mathrm{t}}-\mathrm{D}_{\mathrm{t}-1}\right)+e_{t}
\end{aligned}
$$

The traded spread, AI, and OP components of the spread are calculated for each stock i using the HS model:

$$
\begin{array}{lc}
\text { HSS }=\mathrm{S} & \text { (dollar) } \\
\mathrm{HSAI}=\lambda \cdot \mathrm{S} & (\text { dollar }) \\
\mathrm{HSOP}=(1-\lambda) \cdot \mathrm{S} & (\text { dollar })
\end{array}
$$

iii. MRR model----------- Madhavan, Richardson, and Roomans (1997)

MRR demonstrated that $u_{t}$, the posttrade expected value derived from the price generation process used in their model, can be expressed as

$$
u_{t}=p_{t}-p_{t-1}-(\varphi+\theta) \mathrm{D}_{\mathrm{t}}+(\varphi+\rho \theta) \mathrm{D}_{t-1}
$$

where $\theta$ is the asymmetric information component, $\varphi$ is the cost of order processing, $\lambda$ is the probability that a trade occurs inside the spread, and $\rho$ is the autocorrelation of order flow. As in the MMR model, the generalized method of moments (GMM) is used to identify the parameters and the constant drift implied by the model

$$
\mathrm{E}\left[\begin{array}{l}
D_{t} D_{t-1}-D_{1}^{2} \rho \\
\left|D_{t}\right|-(1-\lambda) \\
\mu_{t}-\alpha \\
\left(\mu_{t}-\alpha\right) D_{t} \\
\left.\left(\mu_{t}-\alpha\right) D_{t-1}\right)
\end{array}\right]=0
$$

The first equation defines the autocorrelation in trade initiation; the second equation represents the crossing probability; the third equation defines the drift term, $\alpha$, as the average pricing error; and the final two equations are defined as OLS normal equations.

We estimated the MRR OP component, $\varphi_{i}$, and AI cost, $\theta_{i}$, in dollar terms for each stock i using

$$
\begin{array}{ll}
\text { MRRS }=2 \times(\theta+\varphi) & (\text { dollar }) \\
\text { MRRAI }=2 \theta & (\text { dollar }) \\
\text { MRROP }=2 \varphi & \text { (dollar) }
\end{array}
$$




\section{Empirical Results and Analysis}

\subsection{Spread Components}

Previous studies have indicated that the reduction of tick size resulted in significantly smaller spreads because it alleviated the binding constraints and intensified market competition, both of which substantially restricted the capacity of market makers to seek excess rents. Gibson et al. (2003) determined that the reduced traded spread in the NYSE can be primarily attributed to the significant decline in the order-processing component, whereas the asymmetric information component remained essentially unchanged. The evidence provided by Gibson et al. (2003) implied that market makers enjoyed an artificially higher spread compared to their actual costs in the fractional pricing regime whereas informed trading displayed no significant distinction between the fractional pricing regime and the decimal pricing regime. Ahn et al. (2007) discovered that the transitory order processing costs and the permanent asymmetric information costs in the TSE significantly declined after tick size was reduced. The evidence derived from the NYSE and TSE implied that the asymmetric information cost was relatively small during pre- and postevents and displayed noticeable increase in proportion because of the dramatic decrease in order-processing costs after tick size reduction.

Table 3 shows the traded spreads and various spread components used in the GKN model, HS model, and MRR model after the TWSE adopted the tighter tick-size schedule on March 1, 2005. The averages per share of traded spreads were uniformly reduced across the test groups in the three-spread decomposition models. In the GKN model, the estimated traded spreads decreased by NT $\$ 0.018$, NT $\$ 0.033$, and NT $\$ 0.364$ for Groups 2,4 , and 5, respectively. The reduced proportion of reduced traded spreads can primarily be attributed to the reduced order-processing component whereas can only be slightly attributed to changes in the asymmetric-information component. In the GKN model, the reduced order processing related to asymmetric information was NT $\$ 0.017 / \mathrm{NT} \$ 0.001$, NT $\$ 0.030 / \mathrm{NT} \$ 0.003$, and NT\$0.336/NT\$0.027 in the three test groups, respectively. Because the proportion of asymmetric information costs was relatively small, the sharp reduction in the order-processing component indicates a significant increase in the proportion of asymmetric information. The average proportion of the asymmetric-information components in the GKN model significantly increased to $5.462 \%, 2.739 \%$, and $8.805 \%$, respectively. The median test results for tick-size changes largely agreed with those of the mean tests. The Wilcoxon intergroup test results demonstrated significant differences in the effects of tick-size on traded spread and the order-processing component between the test groups and control groups. The results were not significant between Group 2 and Group 4, whereas the associations with the high-priced group, Group 5, exhibited a distinct pattern among the test groups. We conjectured that the high-priced group greatly benefited from the reduced tick size by simultaneously reducing traded spread, order-processing costs, and adverse-selection costs in a relatively large magnitude.

Regarding per-share asymmetric-information cost, the results revealed that a relatively small magnitude was applied uniformly before and after the tick-size conversion across the tick-size groups used in the models. Group 5 solely demonstrated a significant decrease after tick-size conversion by NT $\$ 0.027$ and NT $\$ 0.008$ for GKN and MRR, respectively. Under a smaller tick size, high-priced stocks might encourage information gathering because the benefits derived from a lower traded spread and a reduced probability of the spread straddling the efficient price can outweigh the potential threat of front running. 
Table 3. Traded spreads and components of the bid-ask spread on the TWSE in the pre- and post- tick size reduction periods $^{\mathrm{a}}$

\begin{tabular}{|c|c|c|c|c|c|c|c|c|c|c|c|c|c|c|c|c|c|c|}
\hline & \multicolumn{9}{|c|}{ Trade - Spread ( NT\$ ) } & \multicolumn{9}{|c|}{ Order - Processing ( NT\$ ) } \\
\hline & \multicolumn{3}{|c|}{ GKN model } & \multicolumn{3}{|c|}{ HS model } & \multicolumn{3}{|c|}{ MRR model } & \multicolumn{3}{|c|}{ GKN model } & \multicolumn{3}{|c|}{ HS model } & \multicolumn{2}{|c|}{ MRR model } & \multirow[b]{2}{*}{ Diff. $^{c}$} \\
\hline & Pre & Post & Diff. $^{c}$ & Pre & Post & Diff. $^{c}$ & Pre & Post & Diff. $^{c}$ & Pre & Post & Diff. $^{c}$ & Pre & Post & Diff. $^{c}$ & Pre & Post & \\
\hline \multicolumn{19}{|c|}{ Group $1(\mathrm{n}=15)($ Control group$)$} \\
\hline Mean & 0.04 & 0.04 & 0.00 & 0.02 & 0.03 & $0.01 *$ & 0.02 & 0.03 & $0.01 *$ & 0.03 & 0.03 & 0.00 & 0.02 & 0.02 & $0.01 *$ & 0.02 & 0.02 & $0.01 * *$ \\
\hline Median & 0.03 & 0.04 & 0.01 & 0.02 & 0.03 & $0.00+$ & 0.02 & 0.02 & $0.00+$ & 0.02 & 0.03 & 0.01 & 0.02 & 0.02 & 0.01 & 0.02 & 0.02 & $0.00++$ \\
\hline \multicolumn{19}{|c|}{ Group $2(\mathrm{n}=39)$} \\
\hline Mean & 0.06 & 0.05 & $-0.02 * *$ & 0.04 & 0.03 & $-0.01 * *$ & 0.04 & 0.03 & $-0.01 * *$ & 0.05 & 0.03 & $-0.02 * *$ & 0.04 & 0.03 & $-0.01 * *$ & 0.04 & 0.02 & $-0.01 * *$ \\
\hline Median & 0.06 & 0.04 & $-0.02++$ & 0.04 & 0.02 & $-0.02++$ & 0.04 & 0.02 & $-0.02++$ & 0.05 & 0.03 & $-0.02++$ & 0.04 & 0.02 & $-0.01++$ & 0.04 & 0.02 & $-0.02++$ \\
\hline \multicolumn{19}{|c|}{ Group 3 ( $n=28)$ (Control group) } \\
\hline Mean & 0.07 & 0.07 & 0.01 & 0.04 & 0.05 & 0.01 & 0.05 & 0.05 & 0.00 & 0.05 & 0.06 & 0.01 & 0.04 & 0.05 & 0.01 & 0.04 & 0.04 & 0.00 \\
\hline Median & 0.06 & 0.07 & $0.01+$ & 0.04 & 0.04 & 0.00 & 0.04 & 0.04 & 0.00 & 0.05 & 0.05 & 0.00 & 0.04 & 0.04 & 0.00 & 0.04 & 0.04 & 0.00 \\
\hline \multicolumn{19}{|c|}{ Group $4(n=184)$} \\
\hline Mean & 0.12 & 0.09 & $-0.03 * *$ & 0.09 & 0.06 & $-0.02 * *$ & 0.09 & 0.06 & $-0.03 * *$ & 0.10 & 0.07 & $-0.03 * *$ & 0.08 & 0.05 & $-0.03 * *$ & 0.08 & 0.05 & $-0.02 * *$ \\
\hline Median & 0.11 & 0.08 & $-0.04++$ & 0.08 & 0.05 & $-0.03++$ & 0.08 & 0.05 & $-0.03++$ & 0.10 & 0.06 & $-0.04++$ & 0.08 & 0.05 & $-0.03++$ & 0.08 & 0.05 & $-0.03++$ \\
\hline \multicolumn{19}{|c|}{ Group $5(n=24)$} \\
\hline Mean & 0.53 & 0.17 & $-0.36 * *$ & 0.40 & 0.11 & $-0.30 * *$ & 0.41 & 0.11 & $-0.30 * *$ & 0.46 & 0.13 & $-0.34 * *$ & 0.39 & 0.10 & $-0.30 * *$ & 0.36 & 0.10 & $-0.29 * *$ \\
\hline Median & 0.52 & 0.15 & $-0.37++$ & 0.40 & 0.10 & $-0.30++$ & 0.40 & 0.10 & $-0.31++$ & 0.46 & 0.12 & $-0.35++$ & 0.38 & 0.09 & $-0.30++$ & 0.37 & 0.09 & $-0.28++$ \\
\hline \multicolumn{19}{|c|}{ Wilcoxon p-values with Control Group ${ }^{\text {b }}$} \\
\hline Group & vs. Gr & oup 2 & 0.000 & & & 0.000 & & & 0.000 & & & 0.000 & & & 0.000 & & & 0.000 \\
\hline Group & vs. Gr & oup 4 & 0.000 & & & 0.000 & & & 0.000 & & & 0.000 & & & 0.000 & & & 0.000 \\
\hline Group 3 & vs. Gr & oup 5 & 0.000 & & & 0.000 & & & 0.000 & & & 0.000 & & & 0.000 & & & 0.000 \\
\hline \multicolumn{19}{|c|}{ Wilcoxon p-values without Control Group ${ }^{b}$} \\
\hline Group & vs. Gr & oup 4 & 0.119 & & & 0.066 & & & 0.066 & & & 0.055 & & & 0.031 & & & 0.023 \\
\hline Group & vs. Gr & oup 5 & 0.000 & & & 0.000 & & & 0.000 & & & 0.000 & & & 0.000 & & & 0.000 \\
\hline Group & vs. Gr & oup 5 & 0.000 & & & 0.000 & & & 0.000 & & & 0.000 & & & 0.000 & & & 0.000 \\
\hline
\end{tabular}


Table 3 (continued)

\begin{tabular}{|c|c|c|c|c|c|c|c|c|c|c|c|c|c|c|c|c|c|}
\hline & \multicolumn{8}{|c|}{ Asymmetric - Information ( NT\$ ) } & \multicolumn{9}{|c|}{ Asymmetric - Information/ Trade - Spread (\%) } \\
\hline & \multicolumn{2}{|c|}{ GKN model } & \multicolumn{3}{|c|}{ HS model } & \multicolumn{3}{|c|}{ MRR model } & \multicolumn{3}{|c|}{ GKN model } & \multicolumn{3}{|c|}{ HS model } & \multicolumn{2}{|c|}{ MRR model } & \multirow[b]{2}{*}{ Diff. $^{c}$} \\
\hline & Pre Post & Diff.c & Pre & Post & Diff. $^{c}$ & Pre & Post & Diff. $^{c}$ & Pre & Post & Diff. $^{c}$ & Pre & Post & Diff. $^{\mathrm{c}}$ & Pre & Post & \\
\hline \multicolumn{18}{|c|}{ Group $1(n=15)($ Control group $)$} \\
\hline Mean & 0.010 .01 & 0.00 & 0.01 & 0.01 & 0.00 & 0.01 & 0.01 & 0.00 & 25.60 & 24.46 & -1.14 & 17.90 & 16.64 & -1.25 & 22.54 & 20.00 & -2.54 \\
\hline Median & 0.010 .01 & 0.00 & 0.00 & 0.00 & 0.00 & 0.00 & 0.00 & 0.00 & 23.87 & 25.10 & 1.23 & 16.86 & 15.01 & -1.85 & 20.33 & 18.33 & -1.20 \\
\hline \multicolumn{18}{|c|}{ Group $2(n=39)$} \\
\hline Mean & 0.010 .01 & -0.00 & 0.01 & 0.01 & 0.00 & 0.01 & 0.01 & 0.00 & 17.89 & 23.36 & $5.46 * *$ & 10.38 & 15.08 & $4.70 * *$ & 12.79 & 18.29 & $5.49 * *$ \\
\hline Median & $0.01 \quad 0.01$ & -0.00 & 0.00 & 0.00 & 0.00 & 0.00 & 0.00 & 0.00 & 17.14 & 23.32 & $6.18++$ & 8.11 & 15.15 & $7.04++$ & 9.30 & 20.00 & $10.70++$ \\
\hline \multicolumn{18}{|c|}{ Group $3(n=28)($ Control group $)$} \\
\hline Mean & 0.010 .02 & $0.01 *$ & 0.00 & 0.00 & 0.00 & 0.01 & 0.01 & 0.00 & 16.63 & 18.75 & $2.12 *$ & 8.39 & 8.31 & -0.08 & 10.76 & 12.13 & 1.37 \\
\hline Median & $\begin{array}{lll}0.01 & 0.01 \\
\end{array}$ & $0.01+$ & 0.00 & 0.00 & 0.00 & 0.00 & 0.01 & 0.00 & 15.75 & 19.96 & $4.20+$ & 6.68 & 7.36 & 0.68 & 9.12 & 11.96 & 2.84 \\
\hline \multicolumn{18}{|c|}{ Group $4(n=184)$} \\
\hline Mean & 0.020 .02 & $-0.00 * *$ & 0.01 & 0.01 & 0.00 & 0.01 & 0.01 & 0.00 & 17.00 & 19.74 & $2.74 * *$ & 8.04 & 9.57 & $1.53 * *$ & 10.35 & 12.16 & $1.81 * *$ \\
\hline Median & $\begin{array}{lll}0.02 & 0.02 \\
\end{array}$ & $-0.00+$ & 0.01 & 0.01 & 0.00 & 0.01 & 0.01 & 0.00 & 16.28 & 20.02 & $3.74++$ & 6.42 & 9.66 & $3.24++$ & 8.64 & 12.06 & $3.42++$ \\
\hline \multicolumn{18}{|c|}{ Group $5(\mathrm{n}=24)$} \\
\hline Mean & $\begin{array}{lll}0.07 & 0.04\end{array}$ & $-0.03 * *$ & 0.01 & 0.01 & 0.00 & 0.02 & 0.01 & $-0.01 *$ & 12.16 & 20.96 & $8.81 * *$ & 2.82 & 8.30 & $5.48 * *$ & 5.30 & 10.65 & $5.34 * *$ \\
\hline Median & $\begin{array}{lll}0.07 & 0.04 \\
\end{array}$ & $-0.03++$ & 0.01 & 0.01 & 0.00 & 0.02 & 0.01 & $-0.01+$ & 12.32 & 23.35 & $11.02++$ & 1.87 & 9.01 & $7.15++$ & 4.43 & 11.22 & $6.79++$ \\
\hline \multicolumn{18}{|c|}{ Wilcoxon p-values with Control Group ${ }^{\mathrm{b}}$} \\
\hline Group 1 & s. Group 2 & 0.325 & & & 0.832 & & & 0.908 & & & 0.001 & & & 0.000 & & & 0.00 \\
\hline Group 3 & s. Group 4 & 0.025 & & & 0.209 & & & 0.012 & & & 0.022 & & & 0.002 & & & 0.11 \\
\hline Group 3 & s. Group 5 & 0.009 & & & 0.468 & & & 0.005 & & & 0.000 & & & 0.000 & & & 0.00 \\
\hline \multicolumn{18}{|c|}{ Wilcoxon p-values without Control Group ${ }^{\mathrm{b}}$} \\
\hline Group 2 & s. Group 4 & 0.393 & & & 0.191 & & & 0.284 & & & 0.592 & & & 0.034 & & & 0.017 \\
\hline Group 2 & s. Group 5 & 0.139 & & & 0.369 & & & 0.033 & & & 0.002 & & & 0.000 & & & 0.002 \\
\hline Group 4 & s. Group 5 & 0.061 & & & 0.038 & & & 0.096 & & & 0.000 & & & 0.000 & & & 0.000 \\
\hline
\end{tabular}

Notes:

a GKN represents George, Kaul, and Nimalendran (1991); HS represents Huang and Stoll (1997); and MRR represents Madhavan, Richardson, and Roomans (1997). The traded spread, order-processing component, asymmetric-information component (measured in NT\$), and proportion of asymmetric information to traded spread (measured in \%)are all calculated for the 3-month periods before and after March 1, 2005, the date on which the new tick-size rule became effective in the TWSE.

b The $P$ values from the Wilcoxon rank-sum test are reported at the bottom of the table for traded spread, the order-processing component, the asymmetric-information component, and the proportion of asymmetric information. ${ }^{*}$ and ${ }^{* *}$ are the significance at the $5 \%$ and $1 \%$ level based on the $t$ test, respectively. ${ }^{+}$and ${ }^{++}$indicate significance at the $5 \%$ and $1 \%$ level, respectively, based on the Wilcoxon signed-rank test.

c ${ }^{*}$ and ${ }^{* *}$ respectively indicate the $5 \%$ and $1 \%$ significance level based on the $t$ test; ${ }^{+}$and ${ }^{++}$respectively indicate the $5 \%$ and $1 \%$ significance level based on the Wilcoxon signed-rank test.

We observed that the proportion of asymmetric information components uniformly increased among the test groups after the tick-size change, whereas the control groups generally showed decreasing but not statistically significant results. The high-priced Group 5 generated the largest proportional increases of 8.805\%, 5.483\%, and 5.343\% for GKN, HS, and MRR, respectively. Contrasted with the other groups, Group 5 uniformly exhibited the lowest proportions of asymmetric information during the tick-size conversion, which were $12.156 \%, 2.816 \%$, and $5.302 \%$ during the preevent, and $20.961 \%, 8.299 \%$, and $10.645 \%$ during the postevent. The relatively low proportion of the asymmetric-information component implied that relatively high residual order processing costs were incurred by Group 5. The TWSE represents a major trading protocol among emerging markets. After the tick size was reduced, 
the average proportion of the asymmetric-information component increased to $21.453 \%, 11.578 \%$, and $14.643 \%$ for GKN, HS, and MRR, respectively. For cases in developed markets, the asymmetric-information component comprised $59.04 \%$ of the NYSE under the decimal pricing regime analyzed by Gibson et al. (2003) and the TSE incurred $43.21 \%$ after the tick size was reduced, as observed by Ahn et al. (2007). By contrast, the TWSE exhibited a substantially smaller contribution of asymmetric information and inventory costs in the observed traded spreads. Although the distinct market microstructure or trading mechanisms might account for the differentials, the present results imply that the revenues of per share liquidity provision in the TWSE were much higher than those observed in the developed markets were. We determined that further reducing the minimal price variation and the optimal tick size of the TWSE is possible and is worthy of special attention among market traders, regulators, and researchers.

\subsection{Spread Components and Trading Activity}

Previous studies have suggested that the proportional per share spread components are closely related to the idiosyncratic attributes of individual stocks. Demsetz (1968) postulated that stocks with a large trade-volume demonstrate fast execution and produce low order-processing costs. Hasbrouck (1988) concluded that low trade-volume stocks involve higher-order processing costs because these stocks rely on the matching mechanism offered by market specialists. Copland and Stoll (1990), Lin et al. (1995), and McInish and Van Ness (2002) have confirmed the inverse relationship between order-processing costs and trading activities. They reported a positive association between asymmetric-information costs and the proxy of the number of trades. Easley and O'Hara (1987) and Ahn, Hamao, and Ho (2002) have empirically verified the inclination of informed investors to trade high-volume stocks, and that a large trade size can generate considerable information dissemination. We postulated that the reduced tick size resulted in reduced order-processing costs for high-volume stocks, whereas the effect on asymmetric-information costs is to be determined empirically.

We partitioned each test group into high-volume and low-volume subgroups according to the medium of preevent trading volume to analyze the effect of tick-size conversion on the components of traded spreads. Panel A of Table 4 shows that high-volume stocks and low-volume stocks uniformly generated significant decreases in order-processing costs after the reduction of tick size, which were estimated using the three models. Moreover, the magnitude of cost-saving among high-volume stocks was relatively larger than that among low-volume stocks. Particularly the results indicated that the greatest cost reduction occurred in the high-volume subgroup of Group 5 and accounted for $78.40 \%, 81.03 \%$, and $81.14 \%$ for GKN, HS, and MRR, respectively. The Wilcoxon rank-sum test confirmed the significant results derived from parametric $t$ tests. The evidence agreed with that of McInish and Van Ness (2002) that liquidity providers of high-volume stocks can experience a large reduction in economic rent after tick-size conversion. By contrast, Panel B of Table 4 shows that no unanimous conclusions can be made regarding the asymmetric-information components of high-volume and low-volume stocks after tick-size changes occur. Only the low-volume subgroups of Groups 4 and 5 displayed a significant improvement in adverse-selection costs, and no high-volume stocks achieved significant cost-saving for the asymmetric-information component. We will further investigate the influence of trading activity on the tick-size mechanism in Section 3.4 Cross-sectional Regression Analysis. 
Table 4. Relationship between changes in the components of the bid-ask spread and trading activity

\begin{tabular}{|c|c|c|c|c|c|c|c|c|c|c|c|c|c|c|c|c|c|c|c|c|c|}
\hline \multicolumn{8}{|c|}{ Panel A: } & \multicolumn{7}{|c|}{ Order-Processing (NT\$) } & & & & & & & \\
\hline & \multicolumn{7}{|c|}{ GKN model } & \multicolumn{7}{|c|}{ HS model } & \multicolumn{7}{|c|}{ MRR model } \\
\hline & Pre & & Post & & \%Change & & & Pre & & Post & & $\%$ Change & & & Pre & & Post & & $\%$ Change & & \\
\hline & Mean & Med. & Mean & Med. & Mean $^{c}$ & Med. ${ }^{\mathrm{c}}$ & $\mathrm{P}-\mathrm{V}^{\mathrm{b}}$ & Mean & Med. & Mean & Med. & Mean $^{\mathrm{c}}$ & Med. $^{\mathrm{c}}$ & $\mathrm{P}-\mathrm{V}^{\mathrm{b}}$ & Mean & Med. & Mean & Med. & Mean $^{c}$ & Med. ${ }^{\mathrm{c}}$ & $\mathrm{P}-\mathrm{V}^{\mathrm{b}}$ \\
\hline \multicolumn{22}{|c|}{ Group $2(\mathrm{n}=39)$} \\
\hline High & 0.05 & 0.05 & 0.02 & 0.02 & $-56.00 * *$ & $-57.07++$ & 0.00 & 0.04 & 0.04 & 0.02 & 0.01 & $-59.03 * *$ & $-61.16++$ & 0.00 & 0.04 & 0.04 & 0.02 & 0.01 & $-59.65 * *$ & $-61.28++$ & 0.00 \\
\hline Low & 0.05 & 0.05 & 0.05 & 0.05 & $-12.31 *$ & $-4.09+$ & & 0.04 & 0.04 & 0.04 & 0.04 & -9.84 & -10.36 & & 0.04 & 0.04 & 0.03 & 0.03 & -10.51 & -23.55 & \\
\hline \multicolumn{22}{|c|}{ Group $4(n=184)$} \\
\hline High & 0.10 & 0.10 & 0.06 & 0.06 & $-40.71 * *$ & $-43.40++$ & 0.00 & 0.08 & 0.08 & 0.05 & 0.045 & $-42.01 * *$ & $-43.99++$ & 0.00 & 0.08 & 0.08 & 0.05 & 0.04 & $-42.33 * *$ & $-44.40++$ & 0.00 \\
\hline Low & 0.10 & 0.10 & 0.08 & 0.07 & $-19.61 * *$ & $-22.87++$ & & 0.08 & 0.07 & 0.06 & 0.054 & $-17.86 * *$ & $-25.20++$ & & 0.07 & 0.07 & 0.06 & 0.05 & $-19.16 * *$ & $-25.73++$ & \\
\hline \multicolumn{22}{|c|}{ Group $5(\mathrm{n}=24)$} \\
\hline High & 0.49 & 0.49 & 0.11 & 0.10 & $-78.40 * *$ & $-79.27++$ & 0.00 & 0.43 & 0.45 & 0.08 & 0.08 & $-81.03 * *$ & $-81.58++$ & 0.00 & 0.43 & 0.44 & 0.08 & 0.08 & $-81.14 * *$ & $-81.96++$ & 0.00 \\
\hline Low & 0.44 & 0.44 & 0.15 & 0.14 & $-66.32 * *$ & $-69.44++$ & & 0.35 & 0.35 & 0.11 & 0.11 & $-68.54 * *$ & $-69.71++$ & & 0.35 & 0.34 & 0.11 & 0.10 & $-68.36 * *$ & $-70.16++$ & \\
\hline
\end{tabular}

Panel B:

Asymmetric Information ( NT\$ )

\begin{tabular}{|c|c|c|c|c|c|c|c|c|c|c|c|c|c|c|c|c|c|c|c|c|c|c|}
\hline & \multicolumn{8}{|c|}{ GKN model } & \multicolumn{7}{|c|}{ HS model } & \multicolumn{7}{|c|}{ MRR model } \\
\hline & Pre & & Post & & \%Chang & & & & Pre & & Post & & $\%$ Change & & & Pre & & Post & & $\%$ Change & & \\
\hline & Mean & Med. & Mean & Med. & Mean & & Med. $^{\mathrm{c}}$ & $\mathrm{P}-\mathrm{V}^{\mathrm{b}}$ & Mean & Med. & Mean & Med. & Mean $^{\mathrm{c}}$ & Med. ${ }^{\mathrm{c}}$ & $\mathrm{P}-\mathrm{V}^{\mathrm{b}}$ & Mean & Med. & Mean & Med. & Mean $^{c}$ & $\operatorname{Med}^{\mathrm{c}}$ & $\mathrm{P}-\mathrm{V}^{\mathrm{b}}$ \\
\hline \multicolumn{23}{|c|}{ Group $2(n=39)$} \\
\hline High & 0.01 & 0.01 & 0.01 & 0.01 & -7.29 & & -7.92 & 0.58 & 0.00 & 0.00 & 0.00 & 0.00 & 9.61 & $17.00+$ & 0.15 & 0.00 & 0.00 & 0.00 & 0.00 & 8.43 & -7.55 & 0.79 \\
\hline Low & 0.02 & 0.02 & 0.02 & 0.02 & -5.07 & & -17.28 & & 0.01 & 0.01 & 0.01 & 0.01 & 8.19 & 12.45 & & 0.01 & 0.01 & 0.01 & 0.01 & 4.62 & 4.31 & \\
\hline \multicolumn{23}{|c|}{ Group $4(n=184)$} \\
\hline High & 0.01 & 0.01 & 0.01 & 0.01 & -11.97 & & 19.74 & 0.00 & 0.00 & 0.00 & 0.00 & 0.00 & -4.06 & 11.68 & 0.24 & 0.01 & 0.00 & 0.00 & 0.00 & -9.25 & -2.92 & 0.81 \\
\hline Low & 0.04 & 0.03 & 0.03 & 0.03 & -12.71 & $* *$ & $-15.26++$ & & 0.01 & 0.01 & 0.01 & 0.01 & -10.12 & -2.29 & & 0.01 & 0.01 & 0.01 & 0.01 & -9.75 & -10.59 & \\
\hline \multicolumn{23}{|c|}{ Group $5(n=24)$} \\
\hline High & 0.02 & 0.01 & 0.02 & 0.01 & -33.60 & & 62.78 & 0.04 & 0.00 & 0.00 & 0.01 & 0.00 & 9.06 & 9.88 & 0.19 & 0.01 & 0.01 & 0.01 & 0.01 & -36.01 & -38.45 & 0.21 \\
\hline Low & 0.11 & 0.11 & 0.07 & 0.06 & -41.65 & $* *$ & $-49.53++$ & & 0.02 & 0.01 & 0.01 & 0.01 & -14.83 & 5.38 & & 0.03 & 0.03 & 0.02 & 0.02 & -41.12 & -33.11 & \\
\hline
\end{tabular}

Notes:

a GKN represents George, Kaul, and Nimalendran (1991); HS represents Huang and Stoll (1997); and MRR represents Madhavan, Richardson, and Roomans (1997). The traded spread, order-processing component, and asymmetric-information component (measured in NT\$) were all calculated for the 3-month periods before and after March 1, 2005, the date on which the new-tick size rule became effective in the TWSE.

b The $P$ values refer to the Wilcoxon rank-sum test for analyzing the equality of the percentage changes in the order-processing component and the asymmetric-information component, between the paired samples in each test group (high-volume vs. low-volume subgroups).

c ${ }^{*}$ and ${ }^{* *}$ respectively indicate the $5 \%$ and $1 \%$ significance level based on the $t$ test; ${ }^{+}$and ${ }^{++}$respectively indicate the $5 \%$ and $1 \%$ significance level based on the Wilcoxon signed-rank test.

\subsection{Spread Components: Trades Conditional on Size}

\section{i. Empirical design}

Previous studies have indicated that decreased binding constraints can deliver a smaller spread and a thinner limit order book. Overall, small traders can enjoy reduced traded costs, (Note 2) whereas large institutional orders have become more sensitive to market depth and are relatively disadvantaged by the scarcity of quoted depth for their size. (Note 3) Jones and Lipson (2001) used a sample of institutional trades and directly measured the changes in realized execution costs during the switch from the eights regime to the sixteenths regime. Bollen and Busse (2006) employed CAPM to estimate actively managed funds and determined that their transaction costs significantly 
increased after narrowing tick size. We specified three trade-size groups to proxy institution-retail types and empirically reexamined the effect of TWSE tick-size changes on various market traders.

We classified a stock of a tick-size category into small, medium, and large subgroups according to the quantiles of $1 / 3$ and $2 / 3$ tick size within the tick-size category. Three dummy variables for small-, medium-, and large-trade groups were assigned in the GKN model as follows:

$$
\begin{array}{rlrl}
2 \mathrm{RD}_{\mathrm{t}}=\pi_{0}+\pi^{\mathrm{s}} \mathrm{S}_{\mathrm{q}, \mathrm{t}}^{\mathrm{s}}\left(\mathrm{Q}_{\mathrm{t}}^{\mathrm{s}}-\mathrm{Q}_{\mathrm{t}-1}^{\mathrm{s}}\right)+\pi^{\mathrm{m}} \mathrm{S}_{\mathrm{q}, \mathrm{t}}^{\mathrm{m}}\left(\mathrm{Q}_{\mathrm{t}}^{\mathrm{m}}-\mathrm{Q}_{\mathrm{t}-1}^{\mathrm{m}}\right)+\pi^{1} \mathrm{~S}_{\mathrm{q}, \mathrm{t}}^{\mathrm{l}}\left(\mathrm{Q}_{\mathrm{t}}^{\mathrm{l}}-\mathrm{Q}_{\mathrm{t}-1}^{1}\right)+\varepsilon_{\mathrm{t}} \\
\mathrm{Q}_{\mathrm{t}}^{\mathrm{s}}=\mathrm{D}_{\mathrm{t}} & & \text { if trade size is at } \mathrm{t} \leqq \text { trade size of quantile at } 1 / 3 \\
& =0 & & \text { otherwise } \\
\mathrm{Q}_{\mathrm{t}}^{\mathrm{m}} & =\mathrm{D}_{\mathrm{t}} & & \text { trade size of quantile at } 1 / 3<\text { if trade size at } \mathrm{t}<\text { trade size of quantile at } 2 / 3 \\
& =0 & & \text { otherwise } \\
\mathrm{Q}_{\mathrm{t}}{ }^{1} & =\mathrm{D}_{\mathrm{t}} & & \text { if trade size is at } \mathrm{t} \geqq \text { trade size of quantile at } 2 / 3 \\
& =0 & & \text { otherwise }
\end{array}
$$

where $\mathrm{Q}_{\mathrm{t}}^{\mathrm{s}}, \mathrm{Q}_{\mathrm{t}}{ }^{\mathrm{m}}$, and $\mathrm{Q}_{\mathrm{t}}{ }^{1}$ are indicator variables for small-, medium-, and large-size trades, respectively.

Gibson et al. (2003) reported that quoted spread, traded spread, and the order-processing component uniformly and monotonically decreased in trade size after the market converted from a fractional-pricing to a decimal-pricing regime. They indicated that the reduced asymmetric-information component was indistinguishable among various trade sizes and concluded that the significant decline in traded spread was largely attributed to the reduced per share order-processing cost and was not associated with the changes in asymmetric-information cost.

\section{ii. Results}

We reported the empirical results of the GKN model in Table 5 because of space limitations and because the other two models provided similar conclusions. First, the empirical results demonstrated that trade spread uniformly declined for the three trade-size groups among the test groups after tick size was reduced. Group 5 particularly exhibited a substantial reduction of NT $\$ 0.364$, NT $\$ 0.365$, and NT $\$ 0.359$, for the small, medium, and large groups, respectively. The order-processing costs displayed a pattern identical to that of traded spread and indicated a reverse relationship with trade size. The most noticeable reduction of order-processing costs was observed in the high-priced Group 5, which was NT $\$ 0.340$, NT $\$ 0.339$, and NT $\$ 0.328$ for the small, medium, and large groups, respectively. Both the $t$ test and nonparametric Wilcoxon rank-sum test indicated that retail traders and institutional traders benefitted from decreased trade spread and order-processing costs after narrowing tick size. Second, the results revealed a significant reduction, but a relatively small magnitude of adverse-selection costs occurred in the test groups after the tick-size change. The high-priced Group 5 generated the greatest cost saving for the large subgroup, shown by NT $\$ 0.024$, NT $\$ 0.026$, and NT $\$ 0.031$ for the small, medium, and large groups, respectively. The reduced traded spread can primarily be attributed to diminished order-processing costs and is not associated with the changes in the asymmetric-information components. Consequently, the ratio of asymmetric-information costs to traded spread significantly increased across groups of various trade sizes after the tick-size conversion occurred, and the large-trade groups obtained a relatively smaller proportion of the asymmetric-information costs. Third, the nonparametric Wilcoxon tests for analyzing the inter-groups and within-test groups revealed that the trade-size effects were significant for the traded spreads and order-processing costs, whereas no definite conclusions could be made regarding the asymmetric-information costs. 
Table 5. Traded spread and components of the bid-ask spread on the TWSE in the pre- and post- tick size reduction periods for small, medium and large trades. ${ }^{\mathrm{a}}$

\begin{tabular}{|c|c|c|c|c|c|c|c|c|c|c|c|c|c|c|c|c|c|c|}
\hline & \multicolumn{9}{|c|}{ Trade - Spread ( NT\$ ) } & \multicolumn{9}{|c|}{ Order - Processing ( NT\$ ) } \\
\hline & \multicolumn{3}{|c|}{ Small } & \multicolumn{3}{|c|}{ Medium } & \multicolumn{3}{|c|}{ Large } & \multirow[b]{2}{*}{ Pre } & \multicolumn{2}{|c|}{ Small } & \multicolumn{3}{|c|}{ Medium } & \multicolumn{3}{|l|}{ Large } \\
\hline & Pre & Post & Diff. $^{c}$ & Pre & Post & Diff. $^{c}$ & Pre & Post & Diff. $^{c}$ & & Post & Diff. $^{c}$ & Pre & Post & Diff. $^{c}$ & Pre & Post & Diff. $^{c}$ \\
\hline \multicolumn{19}{|c|}{ Group $1(\mathrm{n}=15)($ Control group $)$} \\
\hline Mean & 0.03 & 0.03 & 0.00 & 0.03 & 0.03 & 0.00 & 0.03 & 0.03 & 0.00 & 0.02 & 0.02 & 0.00 & 0.02 & 0.02 & 0.00 & 0.02 & 0.02 & 0.00 \\
\hline Median & 0.03 & 0.03 & 0.00 & 0.03 & 0.03 & $0.00+$ & 0.03 & 0.03 & 0.00 & 0.02 & 0.02 & 0.00 & 0.02 & 0.02 & 0.00 & 0.02 & 0.02 & 0.00 \\
\hline \multicolumn{19}{|c|}{ Group $2(n=39)$} \\
\hline Mean & 0.06 & 0.04 & $-0.02 * *$ & 0.06 & 0.04 & $-0.02 * *$ & 0.06 & 0.04 & $-0.01 * *$ & 0.05 & 0.03 & $-0.02 * *$ & 0.05 & 0.03 & $-0.02 * *$ & 0.05 & 0.03 & $-0.02 * *$ \\
\hline Median & 0.06 & 0.03 & $-0.02++$ & 0.06 & 0.03 & $-0.02++$ & 0.06 & 0.04 & $-0.02++$ & 0.05 & 0.03 & $-0.02++$ & 0.05 & 0.03 & $-0.02++$ & 0.05 & 0.03 & $-0.02++$ \\
\hline \multicolumn{19}{|c|}{ Group $3(n=28)($ Control group $)$} \\
\hline Mean & 0.06 & 0.06 & 0.00 & 0.06 & 0.07 & 0.00 & 0.07 & 0.07 & 0.00 & 0.05 & 0.05 & 0.00 & 0.05 & 0.05 & 0.00 & 0.05 & 0.05 & 0.00 \\
\hline Median & 0.06 & 0.06 & 0.01 & 0.06 & 0.06 & 0.01 & 0.06 & 0.07 & 0.01 & 0.05 & 0.05 & 0.00 & 0.05 & 0.05 & $0.00+$ & 0.05 & 0.05 & 0.00 \\
\hline \multicolumn{19}{|c|}{ Group $4(n=184)$} \\
\hline Mean & 0.12 & 0.09 & $-0.03 * *$ & 0.12 & 0.09 & $-0.03 * *$ & 0.13 & 0.10 & $-0.03 * *$ & 0.10 & 0.07 & $-0.03 * *$ & 0.10 & 0.07 & $-0.03 * *$ & 0.10 & 0.08 & $-0.03 * *$ \\
\hline Median & 0.11 & 0.08 & $-0.04++$ & 0.11 & 0.08 & $-0.04++$ & 0.12 & 0.08 & $-0.03++$ & 0.10 & 0.06 & $-0.04++$ & 0.10 & 0.06 & $-0.04++$ & 0.10 & 0.07 & $-0.03++$ \\
\hline \multicolumn{19}{|c|}{ Group $5(n=24)$} \\
\hline Mean & 0.53 & 0.17 & $-0.36 * *$ & 0.53 & 0.17 & $-0.37 * *$ & 0.54 & 0.18 & $-0.36 * *$ & 0.46 & 0.12 & $-0.34 * *$ & 0.47 & 0.13 & $-0.34 * *$ & 0.46 & 0.14 & $-0.33 * *$ \\
\hline Median & 0.52 & 0.15 & $-0.37++$ & 0.52 & 0.16 & $-0.37++$ & 0.53 & 0.17 & $-0.37++$ & 0.46 & 0.11 & $-0.35++$ & 0.46 & 0.12 & $-0.34++$ & 0.47 & 0.12 & $-0.34++$ \\
\hline \multicolumn{19}{|c|}{ Wilcoxon p-values with Control Group ${ }^{b}$} \\
\hline Group 1 & vs. Gro & oup 2 & 0.001 & & & 0.001 & & & 0.001 & & & 0.001 & & & 0.002 & & & 0.001 \\
\hline Group 3 & vs. Gro & bup 4 & 0.000 & & & 0.000 & & & 0.000 & & & 0.000 & & & 0.000 & & & 0.000 \\
\hline Group 3 & vs. Gro & bup 5 & 0.000 & & & 0.000 & & & 0.000 & & & 0.000 & & & 0.000 & & & 0.000 \\
\hline \multicolumn{19}{|c|}{ Wilcoxon p-values without Control Group ${ }^{\mathrm{b}}$} \\
\hline Group 2 & vs. Gro & bup 4 & 0.008 & & & 0.013 & & & 0.020 & & & 0.013 & & & 0.004 & & & 0.005 \\
\hline Group 2 & vs. Gro & oup 5 & 0.000 & & & 0.000 & & & 0.000 & & & 0.000 & & & 0.000 & & & 0.000 \\
\hline Group 4 & vs. Gro & oup 5 & 0.000 & & & 0.000 & & & 0.000 & & & 0.000 & & & 0.000 & & & 0.000 \\
\hline
\end{tabular}


Table 5 (continued)

\begin{tabular}{|c|c|c|c|c|c|c|c|c|c|c|c|c|c|c|c|c|c|c|}
\hline & \multicolumn{9}{|c|}{ Asymmetric - Information ( NT\$ ) } & \multicolumn{9}{|c|}{ Asymmetric - Information/ Trade - Spread (\%) } \\
\hline & \multicolumn{3}{|c|}{ Small } & \multicolumn{3}{|c|}{ Medium } & \multicolumn{3}{|c|}{ Large } & \multicolumn{3}{|c|}{ Small } & \multicolumn{3}{|c|}{ Medium } & \multicolumn{3}{|c|}{ Large } \\
\hline & Pre & Post & Diff. $^{c}$ & Pre & Post & Diff. $^{c}$ & Pre & Post & Diff. ${ }^{c}$ & Pre & Post & Diff. $^{\mathrm{c}}$ & Pre & Post & Diff. $^{c}$ & Pre & Post & Diff. $^{\mathrm{c}}$ \\
\hline \multicolumn{19}{|c|}{ Group $1(\mathrm{n}=15)($ Control group$)$} \\
\hline Mean & 0.01 & 0.01 & 0.00 & 0.01 & 0.01 & $0.00 *$ & 0.01 & 0.01 & 0.00 & 23.41 & 23.67 & 0.26 & 26.70 & 30.54 & 3.84 & 24.07 & 24.57 & 0.50 \\
\hline Median & 0.01 & 0.01 & 0.00 & 0.01 & 0.01 & $0.00+$ & 0.01 & 0.01 & 0.00 & 23.97 & 25.58 & 1.61 & 27.51 & 31.04 & 3.53 & 24.07 & 25.35 & 1.28 \\
\hline \multicolumn{19}{|c|}{ Group $2(\mathrm{n}=39)$} \\
\hline Mean & 0.01 & 0.01 & $-0.00 * *$ & 0.01 & 0.01 & $-0.00 *$ & 0.01 & 0.01 & -0.00 & 18.20 & 23.56 & $5.36 * *$ & 19.18 & 24.73 & $5.54 * *$ & 19.50 & 24.42 & $4.92 * *$ \\
\hline Median & 0.01 & 0.01 & $-0.00+$ & 0.01 & 0.01 & $-0.00+$ & 0.01 & 0.01 & $-0.00+$ & 16.09 & 23.25 & $7.16++$ & 16.54 & 25.55 & $9.01++$ & 17.58 & 23.45 & $5.88++$ \\
\hline \multicolumn{19}{|c|}{ Group $3(n=28)($ Control group $)$} \\
\hline Mean & 0.01 & 0.01 & 0.00 & 0.01 & 0.01 & 0.00 & 0.01 & 0.01 & 0.00 & 17.00 & 18.56 & 1.56 & 17.02 & 18.20 & 1.18 & 18.34 & 19.35 & 1.01 \\
\hline Median & 0.01 & 0.01 & 0.00 & 0.01 & 0.01 & 0.00 & 0.01 & 0.01 & 0.00 & 15.99 & 21.20 & 5.21 & 16.48 & 19.56 & 3.08 & 15.79 & 20.22 & 4.43 \\
\hline \multicolumn{19}{|c|}{ Group $4(n=184)$} \\
\hline Mean & 0.02 & 0.02 & $-0.00 * *$ & 0.02 & 0.02 & $-0.00 * *$ & 0.03 & 0.02 & -0.01 & 18.03 & 21.49 & $3.46 * *$ & 19.84 & 23.86 & $4.02 * *$ & 21.05 & 22.22 & $1.17 * *$ \\
\hline Median & 0.02 & 0.08 & $-0.00+$ & 0.02 & 0.02 & $-0.00+$ & 0.02 & 0.02 & $-0.00++$ & 18.33 & 22.46 & $4.13++$ & 17.62 & 21.04 & $3.42++$ & 15.93 & 17.77 & $1.84++$ \\
\hline \multicolumn{19}{|c|}{ Group $5(\mathrm{n}=24)$} \\
\hline Mean & 0.07 & 0.04 & $-0.02 * *$ & 0.07 & 0.04 & $-0.03 * *$ & 0.07 & 0.04 & $-0.03 * *$ & 11.95 & 22.46 & $10.51 * *$ & 11.95 & 21.09 & $9.14 * *$ & 12.84 & 19.68 & $6.84 * *$ \\
\hline Median & 0.06 & 0.04 & $-0.02+$ & 0.06 & 0.04 & $-0.02+$ & 0.06 & 0.03 & $-0.03+$ & 11.90 & 24.96 & $13.06++$ & 10.75 & 22.73 & $11.98++$ & 11.92 & 19.80 & $7.88++$ \\
\hline \multicolumn{19}{|c|}{ Wilcoxon p-values with Control Group ${ }^{\mathrm{b}}$} \\
\hline Group & vs. Gr & oup 2 & 0.059 & & & 0.002 & & & 0.088 & & & 0.081 & & & 0.155 & & & 0.039 \\
\hline Group 3 & vs. Gr & oup 4 & 0.246 & & & 0.099 & & & 0.035 & & & 0.006 & & & 0.013 & & & 0.128 \\
\hline Group 3 & vs. Gr & oup 5 & 0.118 & & & 0.097 & & & 0.025 & & & 0.000 & & & 0.000 & & & 0.001 \\
\hline \multicolumn{19}{|c|}{ Wilcoxon p-values without Control Group ${ }^{\mathrm{b}}$} \\
\hline Group 2 & vs. Gr & oup 4 & 0.035 & & & 0.207 & & & 0.322 & & & 0.978 & & & 0.350 & & & 0.286 \\
\hline Group 2 & vs. Gr & oup 5 & 0.482 & & & 0.534 & & & 0.387 & & & 0.001 & & & 0.006 & & & 0.036 \\
\hline Group 2 & vs. Gr & oup 5 & 0.144 & & & 0.312 & & & 0.137 & & & 0.000 & & & 0.000 & & & 0.001 \\
\hline
\end{tabular}

Notes:

a The spread components were estimated using the model provided by George, Kaul, and Nimalendran (1991) for the 3-month periods before and after March 1, 2005, the date on which the new tick-size rule became effective in the TWSE. The traded spread, order-processing cost, and asymmetric-information cost were expressed in NT dollars, and the proportion of asymmetric information was measured using percentages. Trades were classified as small (trade size $\leqq$ trade size at the quantile of $1 / 3$ ), medium (trade size at the quantile of $1 / 3<$ trade size < trade size at the quantile of $2 / 3$ ), and large (trade size $\geqq$ trade size at the quantile of $2 / 3$ ).

b The $P$ values from the Wilcoxon rank-sum test are reported at the bottom of the table for traded spread, the order-processing cost, asymmetric-information cost, and the proportion of asymmetric information.

c ${ }^{*}$ and ${ }^{* *}$ respectively indicate the $5 \%$ and $1 \%$ significance level based on the $t$ test; ${ }^{+}$and ${ }^{++}$respectively indicate the $5 \%$ and $1 \%$ significance level based on the Wilcoxon signed-rank test.

The present results agree with those of Goldstein and Kavajecz (2000), in that tighter spreads and a thinner limit order book are more favorable for small trades and cause institutional traders to divide a large order into small pieces. The evidence of the inverse relationship between the magnitude of reduced order-processing costs and trade size also agreed with that of Chan and Lakonishok (1995) and Keim and Madliavan (1997). The current results indicating that increments of proportional asymmetric-information cost after tick size reduction have an inverse relationship with trade size agree with those of McInish and Van Ness (2002), in that a smaller tick size might discourage information collection and reduce adverse-selection costs. 


\section{Cross-sectional Regression Analysis}

We determined that the effect of reduced tick size and binding constraint exerted more influence on the order-processing component and less on the asymmetric-information costs. We further analyzed the cross-sectional idiosyncratic attributes of trading activity, competition, and information structure documented in McInish and Van Ness (2002) and Ascioglu, Comerton-Forde, and McInish (2010) using regression analysis on the effect of reduced tick size as follows:

$$
\begin{gathered}
\% \Delta O P_{i}=\alpha_{0}+\alpha_{1} \text { Ratio }_{i}+\alpha_{2} \text { LogPrice }_{i}^{\text {pre }}+\alpha_{3} \text { LogANumtrade }_{i}^{\text {pre }} \\
\left(\% \Delta A I_{i}\right) \quad+\alpha_{4} 1 / \text { stdev }_{i}^{\text {pre }}+\alpha_{5} \text { LogTurnover }_{i}^{\text {pre }}+\varepsilon_{\mathrm{i}} \\
\% \Delta O P_{i}=\beta_{0}+\beta_{1} \text { Ratio }_{i}+\beta_{2} \text { LogPrice }_{i}^{\text {pre }}+\beta_{3} \text { LogATrsize }_{i}^{\text {pre }} \\
\left(\% \Delta A I_{i}\right) \quad+\beta_{4} 1 / \text { stdev }_{i}^{\text {pre }}+\beta_{5} \text { LogTurnover }_{i}^{\text {pre }}+\varepsilon_{\mathrm{i}}
\end{gathered}
$$

where $\% \triangle O P_{i}$ and $\% \triangle A I_{i}$ are the respective percentage changes in the order-processing component and asymmetric-information component; Ratio is the ratio of the new tick size to the old tick size and measures the probability that the minimal price variation is a binding constraint on spread widths, with a low Ratio indicating the low likelihood of the binding constraint; LogPrice ${ }_{i}^{\text {pre }}$, LogANumtrade $_{i}^{\text {pre }}$, LogTurnover $_{i}^{\text {pre }}$, LogATrsize $_{i}^{\text {pre }}$, and $1 /$ stdev $_{i}^{\text {pre }}$ are the time-series means of the logarithms of daily closing price, aggregated trading volume, daily

\begin{tabular}{|c|c|c|c|c|c|c|c|c|c|c|c|c|}
\hline \multirow[t]{3}{*}{ Variables } & \multicolumn{12}{|c|}{ Change in Order-Processing Component (\%) } \\
\hline & \multicolumn{5}{|c|}{ GKN } & \multicolumn{3}{|c|}{ HS } & \multirow[b]{2}{*}{ Coeff } & \multirow[b]{2}{*}{$\mathrm{t}$-statistic ${ }^{\mathrm{b}}$} & \multicolumn{2}{|c|}{ MRR } \\
\hline & Coeff & t-statistic ${ }^{b}$ & Coeff & t-statistic ${ }^{b}$ & Coeff & t-statistic ${ }^{b}$ & Coeff & t-statistic ${ }^{b}$ & & & Coeff & t-statistic ${ }^{\mathrm{b}}$ \\
\hline Intercept & 0.360 & $3.38 * *$ & 0.261 & $2.13 *$ & 0.489 & $3.35 * *$ & 0.368 & $2.25 *$ & 0.448 & $3.067 * *$ & 0.360 & $2.22 *$ \\
\hline Ratio & 0.864 & $9.82 * *$ & 0.769 & $7.80 * *$ & 0.904 & $7.50 * *$ & 0.796 & $6.08 * *$ & 0.924 & $7.661 * *$ & 0.812 & $6.25 * *$ \\
\hline LogPrice $^{\text {pre }}$ & -0.247 & $-4.41 * *$ & -0.451 & $-7.22 * *$ & -0.268 & $-3.50 * *$ & -0.499 & $-6.01 * *$ & -0.246 & $-3.201 * *$ & -0.487 & $-5.91 * *$ \\
\hline LogANumtrade ${ }^{\text {pre }}$ & -0.228 & $-11.43 * *$ & & & -0.260 & $-9.52 * *$ & & & -0.264 & $-9.656 * *$ & & \\
\hline LogATrsize $\mathrm{pre}^{\text {re }}$ & & & -0.602 & $-7.36 * *$ & & & -0.675 & $-6.21 * *$ & & & -0.732 & $-6.79 * *$ \\
\hline $1 /$ stedv $^{\text {pre }}$ & 0.001 & 0.089 & 0.002 & 0.13 & -0.007 & -0.38 & -0.007 & -0.32 & 0.003 & 0.154 & 0.006 & 0.28 \\
\hline LogTurnover $^{\mathrm{pre}}$ & 0.029 & 0.825 & -0.129 & -3.61 & 0.016 & 0.34 & -0.165 & $-3.47 * *$ & 0.026 & 0.53 & -0.156 & $-3.32 * *$ \\
\hline F-statistic & $52.36 * *$ & & $31.71 *$ & & $34.55 *$ & & 21.58 & & $34.84 * *$ & & 23.16 & \\
\hline Adjusted $\mathrm{R}^{2}$ & 0.511 & & 0.384 & & 0.405 & & 0.295 & & 0.408 & & 0.311 & \\
\hline
\end{tabular}
turnover, daily aggregated trade size, and the reciprocal of the daily volatility, respectively, during the 3 months before the TWSE tick-size change. (Note 4)

Table 6. Cross-sectional regression of changes in order-processing component. ${ }^{a}$

Notes:

a GKN represents George, Kaul, and Nimalendran (1991); HS represents Huang and Stoll (1997); and MRR represents Madhavan, Richardson, and Roomans (1997). The percentage changes in the time-series average order-processing component are regressed on the ratio of the new tick size to the original tick size (Ratio), the natural $\log$ of the time-series average stock price (LogPrice ${ }^{\text {pre }}$ ), the natural log of the time-series average daily number of trades (LogANumtrade ${ }^{p r e}$ ), the natural log of the time-series average daily mean trade size (LogATrsize ${ }^{p r e}$ ), the inverse of the time-series average standard deviation of returns $\left(1 /\right.$ stdev $\left.^{\text {pre }}\right)$, and the natural log of turnover (LogTurnover ${ }^{\text {pre }}$ ), which were all estimated using data from the 3 months prior to the tick-size conversion.

b $*$ and $* *$ respectively indicate the $5 \%$ and $1 \%$ significance levels.

Table 6 shows the cross-sectional regression analysis results for the proportional changes in the order-processing components that were estimated using the three decomposition models (Note 5) before and after tick size was 
reduced. The empirical results revealed a uniformly positive relationship between Ratio $_{i}$ and $\% \Delta O P_{i}$, which indicated that a high probability of binding constraints causes a high magnitude of reduction in the order-processing component. The price level, LogPrice ${ }_{i}^{p r e}$, exerted significantly negative influences on the $\% \triangle O P_{i}$ across the three decomposition models. The evidence indicated that the order-processing revenue of liquidity provision greatly reduced for the high-priced stocks during the smaller tick-size regime, which is consistent with the result for the high-priced Group 5, which was previously reported in Table 3. Both trading activity proxies, LogANumtrade $e_{i}^{\text {pre }}$ and LogATrsize $e_{i}^{\text {pre }}$, displayed a significantly negative relationship with $\% \triangle O P_{i}$ and indicated that intensive trading-activity stocks reduce order-processing costs because of the reduced tick size, which agrees with the results of McInish and Van Ness (2002). However, the information proxies, LogTurnover ${ }_{i}^{\text {pre }}$ and $1 /$ stdev $_{i}^{\text {pre }}$, provided inconclusive results on the change in order-processing costs during the tick-size conversion.

Table 7 shows the results of cross-sectional regression analysis on the asymmetric-information components estimated using the GKN, HS, and MRR models. Overall, we observed little explanatory power demonstrated by the models that associated with a smaller adjusted $\mathrm{R}^{2}$ and also derived nonsignificant estimated coefficients, particularly from the MRR model. The results on the probability of binding constraints indicated that Ratio ${ }_{i}$ was significant in the HS model, but exerted a significantly negative influence on the change in asymmetric information. The evidence suggests that lifting binding constraints encouraged information collecting and was responsible for the increased adverse-selection cost that occurred after tick-size conversion. The information proxies, LogANumtrade ${ }_{i}^{\text {pre }}$ and $\operatorname{LogATrsize}_{i}^{\text {pre }}$, exhibited a positive relationship with the change in the asymmetric-information components of GKN and HS and indicated a high degree of information asymmetry and high incentives to gather information, which generated greater adverse-selection cost after tick size was reduced. In summary, the cross-sectional regression results provided complementary results regarding the influences of binding constraint, trading activity, and market conditions on order-processing cost and asymmetric-information cost caused by tick-size conversion.

Table 7. Cross-sectional regression of changes in asymmetric information component ${ }^{\mathrm{a}}$

\begin{tabular}{|c|c|c|c|c|c|c|c|c|c|c|c|c|}
\hline \multirow[t]{3}{*}{ Variables } & \multicolumn{12}{|c|}{ Change in Asymmetric Information Component (\%) } \\
\hline & \multicolumn{4}{|c|}{ GKN } & \multicolumn{4}{|c|}{ HS } & \multirow[b]{2}{*}{ Coeff } & \multicolumn{3}{|c|}{ MRR } \\
\hline & Coeff & t-statistic ${ }^{b}$ & Coeff & t-statistic ${ }^{b}$ & Coeff & $\mathrm{t}$-statistic ${ }^{\mathrm{b}}$ & Coeff & $\mathrm{t}$-statistic ${ }^{\mathrm{b}}$ & & t-statistic ${ }^{b}$ & Coeff & t-statistic ${ }^{b}$ \\
\hline Intercept & -2.045 & $-5.93 * *$ & -1.888 & $-5.02 * *$ & -0.638 & -1.54 & -0.894 & $-2.13 *$ & 0.028 & 0.09 & -0.212 & -0.63 \\
\hline Ratio & 0.006 & 0.02 & 0.239 & 0.79 & -1.147 & $-3.35 * *$ & -1.058 & $-3.14 * *$ & 0.181 & 0.67 & 0.204 & 0.76 \\
\hline LogPrice ${ }^{\text {pre }}$ & 0.142 & 0.79 & 0.670 & $3.51 * *$ & 0.410 & 1.88 & 0.653 & $3.06 * *$ & -0.151 & -0.87 & -0.074 & -0.44 \\
\hline LogANumtrade $^{\text {pre }}$ & 0.567 & $8.78 * *$ & & & 0.199 & $2.57 *$ & & & 0.031 & 0.51 & & \\
\hline $\log A \operatorname{Trsize} \mathrm{p}^{\mathrm{pre}}$ & & & 1.608 & $6.42 * *$ & & & 0.981 & $3.51 * *$ & & & 0.416 & 1.86 \\
\hline $1 /$ stedv $^{\text {pre }}$ & 0.037 & 0.86 & 0.030 & 0.65 & 0.008 & 0.15 & -0.017 & -0.33 & 0.028 & 0.68 & 0.010 & 0.25 \\
\hline LogTurnover ${ }^{\mathrm{pre}}$ & -0.180 & -1.56 & 0.209 & 1.92 & -0.210 & -1.52 & -0.095 & -0.78 & 0.032 & 0.29 & 0.038 & 0.39 \\
\hline F-statistic & $17.86 *$ & & $10.41 * *$ & & $4.84 * *$ & & 6.209 ** & & 0.80 & & 1.45 & \\
\hline Adjusted $\mathrm{R}^{2}$ & 0.255 & & 0.161 & & 0.073 & & 0.096 & & 0.016 & & 0.029 & \\
\hline
\end{tabular}

Notes:

a GKN represents George, Kaul, and Nimalendran (1991); HS represents Huang and Stoll (1997), and MRR represents Madhavan, Richardson, and Roomans (1997). The percentage changes in the time-series average order-processing component are regressed on the ratio of the new tick size to the original tick size (Ratio), the natural $\log$ of the time-series average stock price $\left(\right.$ LogPrice $\left.^{\text {pre }}\right)$, the natural log of the time-series average daily number of trades (LogANumtrade $e^{\text {pre }}$ ), the natural log of the time-series average daily mean trade size $\left(\operatorname{LogATrsiz} e^{\text {pre }}\right)$, the inverse of the time-series average standard deviation of returns $\left(1 /\right.$ stdev $\left.^{\text {pre }}\right)$, and the natural log of turnover (LogTurnover $\left.{ }^{\text {pre }}\right)$, all of which were estimated using data obtained during the 3 months prior to the tick-size conversion.

b $*$ and $* *$ respectively indicate the $5 \%$ and $1 \%$ significance levels. 


\section{Conclusion and Remarks}

We comprehensively examined the effect of reduced tick size on the trade spread and its various components by employing data obtained in the TWSE. The major findings are discussed as follows.

First, the results indicated that traded spread and the order-processing component significantly declined after tick-size conversion, whereas the asymmetric-information component exhibited a relatively small reduction. We conjectured that liquidity providers on the limit order book might capture monopolistic rents before switching the tick-size regime, whereas increased market competition among dealers and limit order book traders introduced by a smaller tick size greatly contracted the economic rents for liquidity suppliers. In contrast with developed markets, the TWSE exhibited substantial economic rents for liquidity provision and indicated the capacity and possibility for further reducing the tick size.

Second, the results indicated that stocks with higher preevent liquidity benefited from a greater reduction in order-processing costs compared with those with lower preevent liquidity stocks. The greatest cost-saving occurred in the high-volume stocks of the high-priced Group 5. The evidence suggested that the increased number of trades and amount of dollar volume after tick-size conversion might have compensated for the lost rents caused by the smaller spreads and thinner depth, and induced Pareto improvement for the high-priced stocks.

Third, the results indicated that institutional traders and individual traders significantly improved the trade spread and order-processing component because of the tick-size conversion. However, the thinner limit order book also disadvantaged institutional traders by compelling them to pay more on liquidity provision. The effects of institutional trading on asymmetric-information costs were less significant than those on the traded spread and order-processing costs after tick size was reduced.

Finally, the cross-sectional regression analysis results indicated that stocks with high binding constraints, a high price, and high trading activity generated high proportional reduction in the order-processing component after the tick-size conversion. The trading activity proxies, LogANumtrade ${ }_{i}^{\text {pre }}$ and LogATrsize $_{i}^{\text {pre }}$, exhibited a positive relationship with the change in asymmetric information components, indicating that a high degree of information asymmetry and high incentives to gather information generated greater adverse-selection cost after tick size was reduced.

\section{References}

Ahn, H., C.Q. Cao, \& H. Choe. (1998). Decimalization and Competition among Stock Markets: Evidence from Toronto Stock Exchange Cross-Listed Securities. Journal of Financial Markets, 1, 51-87. https://doi.org/10.1016/S1386-4181(97)00002-5

Ahn, H., J. Cai, K. Chan, \& Y. Hamao. (2007). Tick Size Change and Liquidity Provision on the Tokyo Stock Exchange. Journal of the Japanese and International Economies, 21, 173-194. https://doi.org/10.1016/j.jjie.2005.10.008

Aitken, M., \& C. Comerton-Forde. (2005). Do Reductions in Tick Sizes Influence Liquidity?. Accounting and Finance, 45, 171-184. https://doi.org/10.1111/j.1467-629x.2004.00128.x

Ascioglu, A., C. Comerton-Forde, \& T.H., McInish. (2010). An Examination of Minimum Tick size on the Tokyo Stock Exchange. Japan and the World Economy, 22, 40-48. https://doi.org/10.1016/j.japwor.2009.06.006

Bacidore, J. (1997). The Impact of Decimalization on Market Quality: An Empirical Investigation of the Toronto Stock Exchange. Journal of Financial Intermediation, 6, 92-120. https://doi.org/10.1006/jfin.1997.0213

Bacidore, J., R. Battalio, \& R. Jennings. (2003). Order Submission Strategies, Liquidity Supply, and Trading in Pennies on the New York Stock Exchange. Journal of Financial Markets, 6, 337-362. https://doi.org/10.1016/S1386-4181(03)00003-X

Bacidore, J., R. Battalio, R. Jennings, \& S. Farkas. (2001). Changes in Order Characteristics, Displayed Liquidity, and Execution Quality on the NYSE around the Switch to Decimal Pricing. Working paper, New York Stock Exchange.

Bessembinder, H. (2003). Trade Execution Costs and Market Quality after Decimalization. Journal of Financial and Quantitative Analysis, 38, 747-777. https://doi.org/10.2307/4126742

Bollen, N.P.B., \& J.A. Busse. (2006). Tick Size and Institutional Trading Costs: Evidence from Mutual Funds. Journal of Financial and Quantitative Analysis, 41, 915-937. https://doi.org/10.1017/S0022109000002696

Cai, J., Y. Hamao, \& R. Y. K., Ho. (2008). Tick Size Change and Liquidity Provision for Japanese Stock Trading near $¥$ 1000. Japan and the World Economy, 20, 19-39. https://doi.org/10.1016/j.japwor.2006.08.004 
Cao, C., H. Choe, \& F. Hatheway. (1997). Does the Specialist Matter? Differential Execution Costs and Intersecurity Subsidization on the New York Stock Exchange. Journal of Finance, 52, 1615-1640. https://doi.org/10.1111/j.1540-6261.1997.tb01123.x

Chakravarty, S., R.A. Wood, \& R.A. Van Ness. (2004). Decimals and Liquidity: A Study of the NYSE. Journal of Financial Research, 27, 75-94. https://doi.org/10.1111/j.1475-6803.2004.00078.x

Chakravarty, S., S. Harris, \& R. Wood. (2001). Decimal Trading and Market Impact: The NASDAQ Experience. Working paper, University of Memphis. https://doi.org/10.2139/ssrn.266877

Chakravarty, S., V. Panchapagesan, \& R.A. Wood. (2005). Did Decimalization Hurt Institutional Investor?. Journal of Financial Markets, 8, 400-420. https://doi.org/10.1016/j.finmar.2005.05.002

Chan, L.K.C., \& J. Lakonishok. (1995). The Behavior of Stock Prices Around Institutional Trades. Journal of Finance, 50, 1147-1174. https://doi.org/10.1111/j.1540-6261.1995.tb04053.x

Chung, K.H., C. Charoenwong, \& D.K. Ding. (2004). Penny Pricing and the Components of Spread and Depth Changes. Journal of Banking and Finance, 28, 2981-3007. https://doi.org/10.1016/j.jbankfin.2003.11.001

Comerton-Forde, C., \& J. Rydge. (2006). The Current State of Asia-Pacific Stock Exchanges: A Critical Review of Market Design. Pacific-Basin Finance Journal, 14, 1-32. https://doi.org/10.1016/j.pacfin.2005.05.002

Copeland, T., \& H. Stoll. (1990). Trading Markets. In D.E. Logue (Ed.), Handbook of modern finance (2d ed.). Warren, Gorham, \& Lamont, Boston, MA.

Crouhy, M., \& D. Galai. (1992). The Settlement Day Effect in the French Bourse. Journal of Financial Services Research, 6, 417-435. https://doi.org/10.1007/978-94-011-2180-4_7

Demsetz, H. (1968). The Cost of Transacting. Quarterly Journal of Economics, 82, 33-53. https://doi.org/10.2307/1882244

George, T.J., G. Kaul, \& M. Nimalendran. (1991). Estimation of the Bid-Ask Spread and It's Components: A New Approach. Review of Financial Studies, 4, 623-656. https://doi.org/10.1093/rfs/4.4.623

Gibson, S., R. Singh, \& V. Yerramilli. (2003). The Effect of Decimalization on the Components of the Bid-Ask Spread. Journal of Financial Intermediation, 12, 121-148. https://doi.org/10.1016/S1042-9573(03)00017-2

Glosten, L.R., \& P.R. Milgrom. (1985). Bid, Ask and Transaction Prices in a Specialist Market with Heterogeneously Informed Traders. Journal of Financial Economics, 14, 71-100. https://doi.org/10.1016/0304-405X(85)90044-3

Goldstein, M.A., \& K.A. Kavajecz. (2000). Eighths, Sixteenths and Market Depth: Changes in Tick Size and Liquidity Provision on the NYSE. Journal of Financial Economic, 56, 125-149. https://doi.org/10.1016/S0304-405X(99)00061-6

Harris, L.E. (1994). Minimum Price Variations, Discrete Bid-Ask Spreads and Quotation Sizes. Review of Financial Studies, 7, 149-178. https://doi.org/10.1093/rfs/7.1.149

Harris, L.E. (1999). Trading in Pennies: A Survey of the Issues. Working Paper, University of Southern California.

Hasbrouck, J. (1988). Trades, Quotes, Inventories, and Information.Journal of Financial Economics, 22, 229-252. https://doi.org/10.1016/0304-405X(88)90070-0

Huang, R.D., \& H.R. Stoll. (1997). The Components of the Bid-Ask Spread: A General Approach. The Review of Financial Studies, 10, 995-1034. https://doi.org/10.1093/rfs/10.4.995

Jones, C.M., \& M.L. Lipson. (2001). Sixteenths: Direct Evidence on Institutional Execution Costs. Journal of Financial Economics, 59, 253-278. https://doi.org/10.1016/S0304-405X(00)00087-8

Kadan, O. (2006). So Who Gains from a Small Tick Size?. Journal of Financial Intermediation, 15, 32-66. https://doi.org/10.1016/j.jfi.2004.09.003

Keim, D.B., \& A. Madhavan. (1997). Transactions Costs and Investment Style: An Inter-Exchange Analysis of Institutional Equity Trades. Journal of Financial Economics, 46, 265-292. https://doi.org/10.1016/S0304-405X(97)00031-7

Kuo, S., C. Huang, \& C. Chen. (2010). The Impact of the Change in Tick Size on Transaction Costs and Liquidity: An Empirical Investigation of the Taiwan Stock Exchange. Asia-Pacific Journal of Financial Studies, 39, 524-551. https://doi.org/10.1111/j.2041-6156.2010.01020.x 
Lee, C.M.C., \& M.J. Ready. (1991). Inferring Trade Direction from Intraday Data. Journal of Finance, 46, 733-746. https://doi.org/10.1111/j.1540-6261.1991.tb02683.x

Lin, J.-C., G. Sanger, \& G.G. Booth. (1995). Trade Size and Components of the Bid-Ask Spread. Review of Financial Studies, 8, 1153-1183. https://doi.org/10.1093/rfs/8.4.1153

Madhavan, A., \& S. Smidt. (1991). A Bayesian Model of Intraday Specialist Pricing. Journal of Financial Economics, 30, 99-134. https://doi.org/10.1016/0304-405X(91)90039-M

Madhavan, A., M. Richardson, \& M. Roomans. (1997). Why Do Security Prices Change? A Transaction-Level Analysis of NYSE Stocks. The Review of Financial Studies, 10, 1035-1064. https://doi.org/10.1093/rfs/10.4.1035

McInish, T.H., \& B.F. Van Ness. (2002). An Intraday Examination of the Components of the Bid-Ask Spread. The Financial Review, 37, 507-524. https://doi.org/10.1111/1540-6288.00026

O'Hara, M., \& G.S. Oldfield. (1986). The Microeconomics of Market Making. Journal of Financial and Quantitative Analysis, 21, 361-376. https://doi.org/10.2307/2330686

Porter, D.C., \& D.G. Weaver. 1997). Tick Size and Market Quality. Financial Management, 26, 5-26. https://doi.org/10.2307/3666124

Rhee, S.G., \& R.P. Chang. (1992). The Microstructure of Asian Equity Market. Journal of Financial Services Research, 6, 437-454. https://doi.org/10.1007/978-94-011-2180-4_8

Stoll, H.R. (1978). The Supply of Dealer Services in Securities Markets. Journal of Finance, 33, 1133-1151. https://doi.org/10.1111/j.1540-6261.1978.tb02053.x

Van Ness, B. F., R.A. Van Ness, \& R.S. Warr. (2001). How Well do Adverse Selection Components Measure Adverse Selection?. Financial Management, 30, 77-98. https://doi.org/10.2307/3666377

\section{Notes}

Note 1. We also estimated the three decomposition models using the process of seemingly unrelated regression (SUR) proposed by Zellner (1962), which allowed disturbance variances to differ across equations and allowed the disturbance covariances to be non-zero across equations. We obtained similar results that are not reported here, but are available upon request.

Note 2. For example, Porter and Weaver (1997), Ahn, Cao, and Choc (1998), Bacidore, Battalio, and Jennings (2003), Bessembinder (2003), and Chakravmy, Wood, and Van Ness (2004).

Note 3. For example, Goldstein and Kavajecz (2000), Jones and Lipson (2001), Gibson et al. (2003), Bollen and Busse (2006).

Note 4. The sample involved in this regression analysis included only the 247 firms used in the three test groups (Groups 2, 4, and 5).

Note 5. We also specified the interaction terms of Ratio with the probability of binding constraint, and obtained similar results, but when using a smaller adjusted $\mathrm{R}^{2}$. Tables 6 and 7 show only the regressions without interaction terms. 